\title{
The complex genetics and biology of human temperament: a review of traditional concepts in relation to new molecular findings
}

C. Robert Cloninger (10) ${ }^{1,2,3}$, Kevin M. Cloninger ${ }^{3}$, Igor Z Zwir ${ }^{1,4}$ and Liisa Keltikangas-Järvinen ${ }^{5}$

\begin{abstract}
Recent genome-wide association studies (GWAS) have shown that temperament is strongly influenced by more than 700 genes that modulate associative conditioning by molecular processes for synaptic plasticity and long-term learning and memory. The results were replicated in three independent samples despite variable cultures and environments. The identified genes were enriched in pathways activated by behavioral conditioning in animals, including the two major molecular pathways for response to extracellular stimuli, the Ras-MEK-ERK and the PI3K-AKTmTOR cascades. These pathways are activated by a wide variety of physiological and psychosocial stimuli that vary in positive and negative valence and in consequences for health and survival. Changes in these pathways are orchestrated to maintain cellular homeostasis despite changing conditions by modulating temperament and its circadian and seasonal rhythms. In this review we first consider traditional concepts of temperament in relation to the new genetic findings by examining the partial overlap of alternative measures of temperament. Then we propose a definition of temperament as the disposition of a person to learn how to behave, react emotionally, and form attachments automatically by associative conditioning. This definition provides necessary and sufficient criteria to distinguish temperament from other aspects of personality that become integrated with it across the life span. We describe the effects of specific stimuli on the molecular processes underlying temperament from functional, developmental, and evolutionary perspectives. Our new knowledge can improve communication among investigators, increase the power and efficacy of clinical trials, and improve the effectiveness of treatment of personality and its disorders.
\end{abstract}

\section{Introduction}

Observers since antiquity have suggested that children are born with a natural disposition or style of how they react behaviorally and emotionally to diverse physiological, psychosocial, and energetic stimuli ${ }^{1-3}$. This innate biological disposition was called a person's temperament and originally referred to a person's animal-like nature as manifest in habitual patterns of automatic activity and

\footnotetext{
Correspondence: C. Robert Cloninger (crcloninger44@gmail.com)

'Department of Psychiatry, Washington University School of Medicine,

St. Louis, MO, USA

${ }^{2}$ School of Arts and Sciences, Department of Psychological and Brain Sciences, and School of Medicine, Department of Genetics, Washington University, St. Louis, MO, USA

Full list of author information is available at the end of the article.
}

emotional reactivity (temper) ${ }^{1-6}$. When measured in this traditional way, temperament is moderately stable on average throughout a person's life span, but can be modified by behavioral conditioning ${ }^{5-8}$. Despite moderate stability, there is also substantial complexity in the development of temperament, including multi-finality (i.e., a particular profile of traits in early childhood may have different outcomes later) and equi-finality (i.e., different profiles of traits in early childhood may have the same outcome later) ${ }^{9-12}$.

In contrast, the other aspects of personality that were presumed since antiquity to distinguish humans from ancestral animals were collectively called a person's character. Kant defined character as what people make of 
themselves intentionally ${ }^{3}$. Put another way, character is the self-regulatory aspect of personality-that is, the way a person shapes and adapts responses to ever-changing external and internal conditions ${ }^{6}$. These self-regulatory processes include the executive, legislative, and judicial functions necessary for mental self-government and selfactualization of identity ${ }^{13}$. When measured in this way, the self-regulatory aspects of personality develop in incremental steps across the life span as people learn episodically from their personal, social, and cultural experiences what goals and activities interest them and why some goals may be more valuable and fulfilling than others $^{13-15}$.

Many modern scholars and researchers have suggested a variety of empirical ways to distinguish temperament from other aspects of personality ${ }^{7,16-22}$. Others prefer to lump all aspects of personality together in profiles or sets of linear factors, suggesting that adult personality is essentially a culturally conditioned expression of childhood temperament ${ }^{23,24}$ despite their modest and complex patterns of empirical association ${ }^{10-14,25-29}$. Nevertheless, temperament involves emotional drives that are irrational and vary quantitatively in strength, whereas the selfregulatory components of personality have several properties that qualitatively distinguish them from temperament, as summarized in Table 1. Temperament has traditionally been distinguished from other aspects of personality by observations about its neurobiology, appearance in infancy, distinctive styles of automatic behavioral and emotional reactions, absence of intentional self-control or self-awareness, stability across the life span, heritability, and/or the evolutionary conservation of underlying molecular processes ${ }^{1-8,13-19,30-40}$.

Unfortunately, the various criteria suggested to define temperament do not overlap fully and can even contradict one another at times. For example, high heritability or developmental stability has each been used as a criterion for temperament, which leads to disagreements about how to define temperament because they do not identify the same individuals ${ }^{7,8,41}$. Development in infancy is another criterion used to identify components of temperament, but not all cognitive-behavioral features that develop in infancy involve patterns of automatic reactivity that are highly conserved in the evolution of all animals: in particular, some aspects of executive attention and effortful self-control emerged only late in evolution among great apes ${ }^{42,43}$ but begin to develop in early childhood and then mature in steps across the life $\operatorname{span}^{17,19}$. Nevertheless, some recent temperament theorists have included such self-regulatory functions as temperament on the basis of their being heritable and beginning to emerge in early childhood ${ }^{17}$, even though they do not satisfy the other traditional distinguishing features of temperament.

Such definitional inconsistencies have arisen in part for the convenience of investigators with expertise in working with particular methods and samples. For example, some temperament investigators focus on cross-sectional assessments of young children and focus on whatever is present in early childhood. Others do longitudinal studies and focus on developmental stability, while others study inheritance in family and twin studies.

Table 1 Features traditionally used to distinguish temperament from character (i.e., other aspects of personality)

\begin{tabular}{|c|c|c|c|}
\hline $\begin{array}{l}\text { Component of } \\
\text { Personality }\end{array}$ & Temperament & Character & References \\
\hline Biology & $\begin{array}{l}\text { Presumed to be strongly biologically determined by } \\
\text { innate predisposition ("constitution"), and objectively } \\
\text { related automatic behavioral and emotional reactions }\end{array}$ & $\begin{array}{l}\text { Often suggested to be learned by experience, but such } \\
\text { learning may be regulated by innate predispositions to } \\
\text { learn in response to personal, social, and cultural } \\
\text { experience and subjective processes in self-awareness }\end{array}$ & $1-7,18,19,30-34$ \\
\hline Behavior & Automatic activity \& emotionality & Regulation of behavior by Goals and Values & $1-4$ \\
\hline Learning & Procedural (How) & Intentional (What) and Evaluative (When/Where/Why) & $1,2,5,6$ \\
\hline Emotion & Basic/primary (e.g., fear, happiness) & Differentiated/secondary (e.g., shame, compassion) & $18,30-34$ \\
\hline Development & Moderately stable from infancy onward & $\begin{array}{l}\text { Appears after infancy and matures by succession of } \\
\text { later steps into adulthood }\end{array}$ & $1-3,6,7,19$ \\
\hline Heritability & Strong \& independent of social learning and culture & $\begin{array}{l}\text { Either weak or strong, \& influenced by social and } \\
\text { cultural learning (norm-favoring) }\end{array}$ & $6,18,33,35,37$ \\
\hline Evolution & $\begin{array}{l}\text { Temperament as habit learning is highly conserved in all } \\
\text { animals }\end{array}$ & $\begin{array}{l}\text { Intentional self-regulatory functions begin to be } \\
\text { expressed as basic emotions and attachments in } \\
\text { mammals and become well-developed in higher } \\
\text { primates }\end{array}$ & $4,33,36,38,39,42$ \\
\hline
\end{tabular}


In addition, temperament investigators have sometimes relied too heavily on simplistic dichotomies like nature versus nurture, biology versus learning, and genes versus environment. Such dichotomies are totally inadequate to describe the complex phenotypic, genotypic, and environmental architecture of human personality ${ }^{25-27}$. For example, human beings have three distinct systems of learning and memory that are strongly associated with different components of personality: associative conditioning (i.e., how we learn to react automatically, including classical and operant conditioning), intentionality (i.e., what we learn as goals to purposefully seek, including self-direction and social cooperation for personal or mutual benefit), and self-awareness (i.e., when, where, and why we learn, including autobiographical memory with imaginative shifts in perspective taking underlying science, art, and spirituality) ${ }^{27,44-46}$. Each of these systems of learning is dissociable from the others, and each is moderately heritable, related to distinct brain circuitry, and their integration across the life span involves strong gene-environmental interactions in adapting to a wide variety of physiological, psychosocial, and energetic stimuli ${ }^{27}$.

We hypothesized that the distinction between temperament and character was more likely to be specified by identifying which system of learning and memory underlies temperament, not whether temperament is due to nature (genes and biology) rather than nurture (environment and learning $)^{6,25,26}$. Consequently, the effective translation of knowledge about temperament requires attention to the complex architecture of personality along with knowledge of its evolution and complex patterns of development in individuals ${ }^{8,14,42,47-49}$.

Fortunately, we have recently used data-driven methods to identify single-nucleotide polymorphisms (SNPs) that map to 972 genes that explained nearly all the variability in temperament and character expected from twin studies in three independent samples of Finns, Germans, and Koreans $^{25-27}$. These 972 genes include 245 associated with temperament only, 236 with character only, and 491 with both temperament and character. As shown in Fig. 1, the genes associated with temperament were more often protein-coding DNA genes than those associated with character $^{25-27}$, which were more often long non-coding RNA genes or pseudogenes that influence the regulation of expression of protein-coding genes, coordination of the co-expression of sets of genes, and chromatin remodeling $^{50-52}$. Most of the 736 genes associated with temperament are protein-coding genes involved in cellular processes of synaptic plasticity, associative conditioning, and related processes of stress reactivity and neurotransmission. The genes associated with personality were nearly always expressed in the brain (Supplementary Fig. 1). However, their brain functions frequently depended on

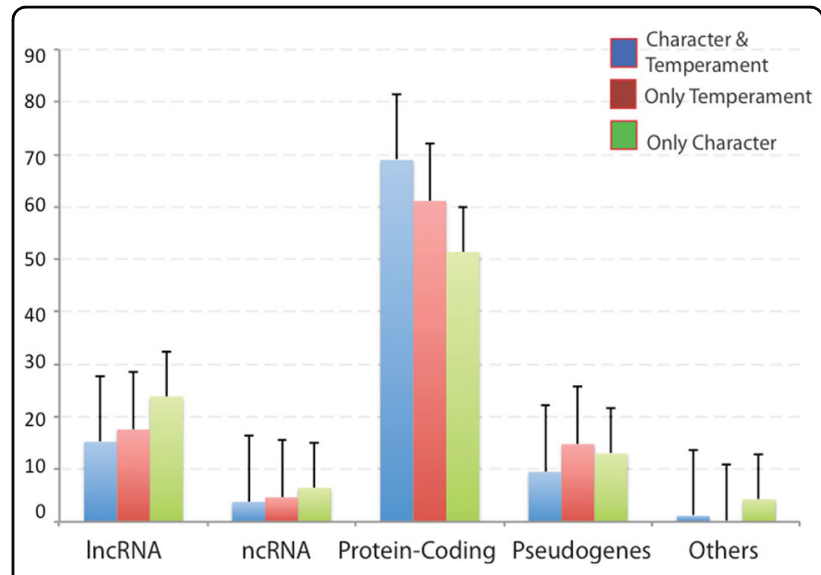

Fig. 1 Distribution of biotypes of 972 genes associated with temperament and/or character, including long non-coding RNA (IncRNA), other non-coding RNA (ncRNA), protein-coding genes, pseudogenes, and others. Genes associated with temperament are more often protein-coding than those associated with character, which are more often genes with regulatory functions (IncRNAs and pseudogenes). Figure is reproduced from Fig. 4c of Zwir et al. ${ }^{27}$, Three Genetic-Environmental Networks for Human Personality)

interactions with genes for general housekeeping functions, such as the regulation of energy metabolism, cellular repair, and circadian rhythms, which occur in most or all cell-types and are associated with both temperament and character (Supplementary Fig. 1) ${ }^{53,54}$. These findings confirmed our hypothesis that the highly conserved molecular processes that regulate associative conditioning in experimental animals account for the heritability of human temperament. Our findings were confirmed in blindly independent replications by GWAS ${ }^{25,26}$ and by independent studies of gene expression during habit learning in experimental animals ${ }^{25-27}$.

However, all our studies were conducted using the Temperament and Character Inventory (TCI) in which heritable dimensions of temperament are assessed by scales that measure individual differences in disposition to associative conditioning in response to signals of punishment (i.e., Harm Avoidance: fearful, shy), novelty (i.e., Novelty Seeking: exploratory, impulsive-aggressive), signals of reward (i.e., Reward Dependence: attached, approval-seeking), and intermittent reinforcement (i.e., Persistence: determined, ambitious ${ }^{26}$. Therefore, here we will review the relations of our temperament measures with alternative modern measures of temperament. We will also review the habitual patterns of behavioral activity and emotional reactivity to various physiological, psychosocial, and energetic stimuli expected from traditional concepts of temperament with those observed for the molecular pathways we uncovered for temperament (i.e., Ras-MEK-ERK and PI3K-AKT-mTOR pathways). Finally, we will discuss the research and clinical implications of 
our findings about the complex genetics and biology of temperament for translational psychiatry.

Our new molecular finding and this review of several complementary lines of temperament research provide an excellent opportunity to build consensus within the diverse field of temperament research and practice, which has been lacking ${ }^{17,22}$. We hope to clarify controversies among temperament researchers who use different assessment methods and study different groups of subjects without losing the complementary insights that may be derived from the different strategies that have been employed in studying temperament. Establishing a consensus in which complementary lines of research may help us all to translate the extensive work that has been and is being done into a more comprehensive model of human development could facilitate a more realistic understanding of many complex aspects of temperament and personality that are important for understanding and promoting healthy development.

\section{Partial overlap of concepts of temperament}

Early descriptions of temperament focused on formal features of patterns of habitual behavioral activity and emotional reactivity that could be directly observed to response to environmental perturbations. In particular, seasonal variation in temperature (cold/hot) and rainfall (wet/dry) appeared to elicit individual differences in behavior and emotional reactions, and such observations gave rise to the ancient model of four temperament types ${ }^{2,3,55}$. These ancient temperament types were also distinguishable in terms of emotional style, valence of mood, intensity of arousal, and responses to rewards, novelty, and punishment, as summarized in Supplementary Table 1.

There has been no consensus about the optimal way to measure temperament based on these general distinguishing features, so a variety of measurement approaches have been used ${ }^{7,12,17}$. In order to relate the new molecular findings about the TCI to other models, we will first describe how the TCI measures temperament and then compare it to several alternative measures in order to assess the extent of their concordance conceptually and empirically.

\section{$\mathrm{TCl}$ measures of temperament}

The Temperament and Character Inventory was developed as a neurobiologically-based model of the evolution of learning by extending the research of Jeffrey Gray on the relationship of associative conditioning in experimental animals to adult human personality ${ }^{39,56}$. Put another way, the TCI measures individual differences in behavioral and emotional style, which Thomas and Chess ${ }^{5}$ described as how a person acts automatically from disposition and habit, rather than the intentional and self- regulatory aspects of personality that specify what, when, where, or why they act as they do.

Specifically, the TCI measures four temperament dimensions that have been empirically confirmed to quantify individual differences in associative conditioning and related human brain circuitry: Harm Avoidance (i.e., fearful, pessimistic vs. risk-taking, optimistic) ${ }^{57-59}$, Novelty Seeking (i.e., impulsive, excitable vs. deliberate, reserved) ${ }^{60,61}$, Reward Dependence (i.e., sociable, sentimental vs. detached, objective) ${ }^{58,61}$, and Persistence (i.e., determined, ambitious vs. easily discouraged, underachieving $)^{62,63}$. High and low scorers on all the subscales of TCI temperament and character are given in Supplementary Table 2 to help relate TCI variables to the terminology of other measures. Harm Avoidance is an indicator of negative valence that measures passiveavoidance learning and increased sensitivity to behavioral inhibition in response to fearful stimuli, which is mediated by activation of the amygdala, subgenual cingulate cortex, and the insular salience network ${ }^{59,64,65}$. Novelty Seeking is an indicator of positive valence that measures behavioral activity to approach and explore novel stimuli ${ }^{66,67}$, even if they do not predict rewards ${ }^{61}$. In contrast, Reward Dependence is characterized by social attachment and approach to rewards based on a different pattern of activation of dopaminergic neurons in the nucleus accumbens and substantia nigra from that seen in association with Novelty Seeking ${ }^{61}$ and on oxytocinergic neurons in the hypothalamus ${ }^{68}$. Persistence measures individual differences in rates of extinction of intermittently rewarded behaviors in response to frustrative non-reward, which is mediated by activating a brain circuit connecting the nucleus accumbens, anterior cingulate, and ventrolateral frontal $\operatorname{cortex}^{62,63}$. Furthermore, these brain circuits for behavioral conditioning are modulated by regulation of the co-expression of sets of genes in the two major molecular pathways for response to extracellular stimuli: the Ras-MEK-ERK pathway and the PI3K-AKT-mTOR pathways ${ }^{25-27}$, as will be described after reviewing the relations of the TCI to other ways of measuring temperament in children and adults.

\section{Strelau temperament inventory}

Jan Strelau has produced a well-validated measure of temperament that is perhaps closest to the classical description of temperament by $\mathrm{Kant}^{3,4}$. Rather than speculating about temperaments being mixtures of various bodily fluids, Kant introduced the notion that temperaments could be recognized by observation of the formal characteristics of their behavior, which involve their energetic and temporal style rather than the content, situation, or goals of the behavior. Likewise Strelau observed that the most frequent and consistent indicators of temperament were its biological basis, presence since 
early childhood, appearance in both man and animals, and the formal characteristics of behavior as described by Kant ${ }^{4,69}$. Strelau found that the two formal characteristics of behavior emphasized by Kant (i.e., activity and emotional reactivity) had strong effects on the regulation of a person's style and engagement in various behaviors and situations according to their stimulus value and psychophysiological costs. Accordingly, his inventory, the Formal Characteristics of Behavior-Temperament Inventory (FCB-TI), measures self-reports of six formal characteristics of behavior in adults: Emotional reactivity (i.e., intense arousal), Briskness (i.e., quick tempo of response with mobility and flexibility), Sensory Sensitivity (i.e., low stimulus threshold), Activity (i.e., high energy level and social activity), Perseverance (i.e., persistence of action after cessation of reinforcing stimulation), and Endurance (i.e., tenacity despite long and intense stimulation). He has shown that his measures are moderately heritable and stable, and that they have strong correlations with other measures of temperament and personality, including the TCI, Pavlovian Temperament Survey (PTS), Buss and Plomin's Emotionality-Activity-Sociability (EAS) inventory, the Eysenck Personality Questionnaire-Revised (EPQ-R) ${ }^{4,69}$, and the Revised Dimensions of Temperament Survey (DOTS-R) based on the features of behavioral style reported by Thomas and Chess to be moderately stable throughout childhood and adolescence ${ }^{70}$ (Table 2).

TCI Harm Avoidance was the temperament most strongly correlated with the features of Strelau's inventory, whereas none of the TCI character measures had strong correlations with the formal energetic and temporal characteristics of behavioral style. As shown in Table 2, Emotional Reactivity correlated strongly $(r>0.7)$ with TCI Harm Avoidance and EPQ Neuroticism, and moderately $(0.7>r>0.35)$ with low scores on Pavlovian Mobility and Strength of Excitation and with high scores on negative emotions (distress, fear, anger) on the EAS. Activity is correlated strongly with EPQ Extraversion and moderately with TCI (low Harm Avoidance and high Novelty Seeking). Strelau's formal characteristics were weakly correlated with DOTS-R measures of Thomas and Chess's behavioral styles related to patterns of Adaptability (i.e., approach vs. withdrawal, flexibility vs. rigidity, mood quality) and Attentional Focus (i.e., low distractibility, persistence), but there were no significant correlations with Rhythmicity (i.e., regularity in sleep, eating, or other daily habits). Except for the weak correlations observed for Sensory Sensitivity, all of Strelau's measures of the formal energetic and temporal characteristics of behavioral style have strong to moderate correlations with one or more TCI temperament traits and with factors in other tests, but not with TCI character traits. TCI temperament traits, but not character traits, also show rhythmicity, as discussed later.
The structural concordance of the four TCI temperaments with other measures of temperament has also been confirmed by their joint factor analysis with temperament as measured by the FCB-TI, EAS, and the DOTS-R in the Young Finns Study in 1997 when the 2106 participants were 20-35 years of age (Supplementary Table 3$)^{71}$. Four factors corresponding to the four TCI temperaments were also identified by factor loadings over 0.5 of scales from the other tests: (1) Harm Avoidance along with FCB-TI Emotional Reactivity and EAS Negative Emotionality; (2) Reward Dependence along with EAS Sociability; (3) Novelty Seeking along with EAS and FCB-TI Activity; (4) Persistence along with DOTS-R Persistence. In addition, DOTS-R contained two factors with loadings over 0.5 that were not represented by the other tests: Rhythmicity (regularity in daily activities, sleep, and eating) and Flexibility, as was also observed by Strelau (Table 1).

\section{New York and Colorado surveys of childhood temperament}

The Colorado Childhood Temperament Inventory is a parental report inventory designed to assess the temperament of children from ages 1 to 6 years. It was derived by factor analysis from the features identified by Thomas and Chess in the New York Longitudinal Study and those identified by Buss and Plomin in their original Emotionality-Activity-Sociability-Impulsivity (EASI) inventory ${ }^{72}$. Recent work shows that such parent reports are only slightly biased by the personality and mood of the parents ${ }^{73}$. Using parent interviews and direct observations of children, Thomas and Chess measured temperament in terms of nine dimensions that appear early in childhood: activity, rhythmicity, approach vs. withdrawal, adaptability, intensity of reaction, threshold of responsiveness, quality or valence of mood, distractibility, and attention span/persistence ${ }^{5}$, which were later adapted by Windle in the DOTS-R for adolescents ${ }^{70}$.

In contrast, Buss and Plomin measured temperament in terms of four behavioral factors that they found to be heritable and developmentally stable ${ }^{7,18}$. The two systems overlapped extensively, especially in indicators of sociability, emotionality, and impulsivity. Six temperament factors appeared in the original merger of the two systems $^{72}$. From the EASI, Emotionality (i.e., easily distressed or irritated), Activity (i.e., highly energetic), and Sociability (i.e., easily approached, warmly responsive, prefers presence of friends to being alone) were retained, but EASI impulsivity was divided into two components called Persistence (i.e., persevering, long attention span) and Soothability (i.e., easily calmed and distracted from distress) based primarily on items from the New York Longitudinal Study (NYLS). A sixth factor, Reaction to Food, was also originally contributed by items from the New York Longitudinal Study ${ }^{72}$, but later a factor for 
Table 2 Correlations $(r \times 100)$ of Strelau's self-reports of basic energetic and temporal characteristics in adults with TCI $\left(n=282^{69}\right.$ and other temperament surveys $\left(n=392^{4}\right)$

\begin{tabular}{|c|c|c|c|c|c|c|}
\hline Other inventories & $\begin{array}{l}\text { Emotional } \\
\text { Reactivity } \\
\text { (intense } \\
\text { arousal) }\end{array}$ & $\begin{array}{l}\text { Briskness (quick } \\
\text { tempo, } \\
\text { mobility, } \\
\text { flexibility) }\end{array}$ & $\begin{array}{l}\text { Sensory } \\
\text { Sensitivity (low } \\
\text { stimulus } \\
\text { threshold) }\end{array}$ & $\begin{array}{l}\text { Activity (high } \\
\text { energy and } \\
\text { social activity }\end{array}$ & $\begin{array}{l}\text { Perseverance } \\
\text { (persistence after } \\
\text { cessation of } \\
\text { reinforcing stimuli) }\end{array}$ & $\begin{array}{l}\text { Endurance } \\
\text { (tenacity under } \\
\text { long intense } \\
\text { stimulation) }\end{array}$ \\
\hline \multicolumn{7}{|l|}{$\mathrm{TCl}$} \\
\hline Harm Avoidance & 73 & -51 & -16 & -54 & 48 & -57 \\
\hline Novelty Seeking & -22 & 18 & 16 & 40 & -1 & 6 \\
\hline Reward Dependence & 23 & -1 & 3 & 2 & 36 & -21 \\
\hline Persistence & -20 & 19 & 10 & 21 & 1 & 13 \\
\hline Self-direction & -40 & 29 & 16 & 9 & -34 & 25 \\
\hline Cooperation & -5 & 18 & 19 & -11 & -5 & -4 \\
\hline Self-transcendence & 7 & 0 & 6 & 14 & 12 & -4 \\
\hline \multicolumn{7}{|l|}{ Pavlovian TS } \\
\hline Strength of Inhibition & -30 & 30 & 7 & 5 & -23 & 39 \\
\hline Strength of Excitation & -57 & 49 & 1 & 37 & -38 & 59 \\
\hline Mobility & -46 & 43 & 11 & 30 & -28 & 46 \\
\hline \multicolumn{7}{|l|}{ EAS-TS } \\
\hline Distress & 59 & -38 & -1 & -30 & 40 & -43 \\
\hline Fear & 53 & -42 & -14 & -25 & 41 & -43 \\
\hline Anger & 40 & -20 & 7 & 1 & 31 & -34 \\
\hline Activity & -20 & 31 & 7 & 48 & 2 & 15 \\
\hline Sociability & -17 & 13 & -5 & 47 & -8 & 6 \\
\hline \multicolumn{7}{|l|}{$E P Q-R$} \\
\hline Neuroticism & 72 & -44 & 2 & -21 & 59 & -54 \\
\hline Extraversion & -32 & 27 & 0 & 73 & -11 & 21 \\
\hline Psychoticism & -21 & 5 & -13 & 16 & -27 & 8 \\
\hline \multicolumn{7}{|l|}{ DOTS-R } \\
\hline Activity-general & -8 & 8 & 0 & 29 & 4 & 0 \\
\hline Activity-sleep & 13 & -6 & 2 & 0 & 12 & -13 \\
\hline Approach vs. withdrawal & -26 & 24 & 12 & 37 & -8 & 20 \\
\hline Flexibility vs. rigidity & -33 & 32 & -6 & 17 & 21 & 28 \\
\hline Mood quality & -17 & 18 & 9 & 26 & -7 & 14 \\
\hline Rhythmicity-sleep & 5 & 3 & -2 & -6 & 1 & -4 \\
\hline Rhythmicity-eating & -9 & 6 & -7 & 6 & -9 & 1 \\
\hline Rhythmicity-daily habits & 7 & 9 & -6 & 4 & -2 & -10 \\
\hline Low distractibility & -20 & 22 & -20 & 10 & -13 & 21 \\
\hline Persistence & -14 & 15 & -14 & -1 & -6 & 17 \\
\hline
\end{tabular}

Significant correlations are in bold $(p<0.05)$ or in italic $(p<0.01$ plus $r>0.35)$ 
Shyness (i.e., inhibited and fearful around strangers) from the EAS was substituted as a more general indicator of fearful, inhibited behavior ${ }^{74}$. Impulsivity was dropped when the EASI survey was modified to form the EAS survey (see Table 2) because their measure of impulsivity was made up of heterogeneous features that were not all heritable or present in infancy ${ }^{18}$. Nevertheless, both Persistence and Soothability were retained in the modified $\mathrm{CCTI}^{48}$. The four factors of Emotionality, Activity, Sociability, and Persistence were only weakly correlated with one another, whereas Soothability $(r=-0.42)$ and Reaction to Food $(r=0.25)$ were correlated with Emotionality $(p<0.001)^{72}$.

Thomas and Chess observed that "temperament individuality" was established by 2 or 3 months of age in the NYLS $^{5}$. They identified three temperament subtypes with specific profiles (i.e., configurations of characteristics) that were relatively stable from 2 months to 10 years of age, which they called "easy", "difficult", and "slow to warm up" subtypes ${ }^{5,75-77}$ (Supplementary Table 4). Others have confirmed that the structure and levels of temperament scales and profiles are moderately stable from ages 1 to 5 , and stronger thereafter, using a variety of instruments including the CCTI, EASI, EAS, DOTS-R, and preschool TCI or ratings of temperament profiles based on direct observations in early childhood ${ }^{28,48,78-80}$. However, as previously mentioned, there is also substantial complexity in the development of temperament scales and profiles, including multi-finality and equi-finality ${ }^{9-12,29}$. The original three prototypes described by Thomas and Chess accounted for only $65 \%$ of children, but more advanced prototype matching and clustering methods allow classification of nearly all subjects ${ }^{26,81}$. As a result of the early classification problem, many investigators preferred to emphasize continuous measures of temperament, usually three linear factors corresponding to negative affectivity/ neuroticism, positive affectivity/extraversion, and effortful control/conscientiousness, as in Rothbart's Child Behavior Questionnaire and Early Adolescent Temperament Questionnaire $^{19}$. However, the frequent emphasis on dimensions rather than prototypes may be questioned because of the greater stability of profiles compared to their component scales in complex adaptive systems and developmental studies of temperament ${ }^{1,14}$, the greater value of a profile of the whole person for therapeutic interventions ${ }^{81}$, and now our finding that genotypic influences on temperament are acting on multidimensional profiles, not the individual traits commonly measured in inventories ${ }^{26}$. Fortunately, measurement of multiple temperament dimensions allows both quantification of individual traits and classification of multidimensional prototypes.

The six CCTI temperaments have been found to have strong correlations with the TCI scales in preschoolers, as
Table 3 Correlations $(r \times 100)$ of preschool TCI with Colorado Childhood Temperament Inventory (CCTI) in parent reports on 64 children at age 30 months

\begin{tabular}{lllllllll}
\hline CCTI Dimension & HA & NS & RD & PS & SD & CO & ST & mR $^{2}$ \\
\hline Activity & -18 & 14 & 25 & 0 & 22 & 0 & 16 & 20 \\
Emotionality & $\mathbf{5 7}$ & $\mathbf{6 4}$ & -36 & -9 & $\mathbf{5 7}$ & $-\mathbf{6 3}$ & -25 & $\mathbf{6 3}$ \\
Shyness & $\mathbf{8 2}$ & $\mathbf{2 0}$ & $-\mathbf{5 7}$ & -8 & -33 & -26 & -30 & $\mathbf{7 7}$ \\
Soothability & -46 & $-\mathbf{6 4}$ & $\mathbf{5 6}$ & 4 & $\mathbf{4 2}$ & $\mathbf{5 4}$ & 13 & $\mathbf{5 6}$ \\
Persistence & 1 & -37 & 12 & $\mathbf{8 6}$ & $\mathbf{4 8}$ & $\mathbf{4 5}$ & 29 & $\mathbf{8 3}$ \\
Sociability & $-\mathbf{4 3}$ & -15 & $\mathbf{7 4}$ & 8 & 32 & 30 & 22 & $\mathbf{6 1}$ \\
mR $^{2}$ & $\mathbf{7 6}$ & $\mathbf{6 1}$ & $\mathbf{7 2}$ & $\mathbf{8 4}$ & $\mathbf{5 6}$ & $\mathbf{5 7}$ & 23 & \\
\hline
\end{tabular}

Adapted from Constantino et al. ${ }^{48}$; statistically significant correlations are shown in bold

shown in Table $3^{48}$. The CCTI temperaments accounted for most of the variability in each of the four TCI temperaments $\left(\mathrm{mR}^{2}=61-84 \%\right)$. However, CCTI scales did not significantly represent TCI Self-Transcendence $\left(\mathrm{mR}^{2}\right.$ $=23 \%$ ), which develops along with self-awareness later in childhood and adulthood. On the other hand, TCI scales did not significantly represent CCTI Activity $\left(\mathrm{mR}^{2}=\right.$ $20 \%$ ), which measures restless motor activity, even though they do for other scales of Activity that measure extraverted social activity or persistent and enduring activity (e.g., Table 1, Supplementary Table 3). The relationships between the TCI temperaments with parental reports of preschoolers were strong and similar to those observed with the formal characteristics of behaviors reported by adults in Strelau's work: Harm Avoidance with CCTI Shyness $(r=0.82)$, Novelty Seeking with CCTI Emotional irritability $(r=0.64)$, Reward Dependence with CCTI Sociability $(r=0.74)$, and TCI Persistence with CCTI Persistence $(r=0.86)$. There were also weak to moderate correlations of TCI character traits with temperament as measured by TCI or CCTI, as expected due to the immature but developing functions of Self-directedness and Cooperativeness in self-regulation of Emotionality, Soothability, and Persistence.

\section{Adult temperament and personality inventories}

The TCI scales also have a distinct and consistent pattern of relations with inventories designed to measure temperament or personality traits reported to be heritable and neurobiologically-based in adults (Table 4). Data are available about the Adult Temperament Questionnaire (ATQ) of Evans and Rothbart ${ }^{82}$, the ZuckermanKuhlman Personality Questionnaire $(\mathrm{ZKPQ})^{83}$, the Emotionality-Activity-Sociability (EAS) Temperament Survey $^{29}$, the revised Eysenck Personality Questionnaire ${ }^{83}$, and the revised NEO Personality Inventory of Costa and $\mathrm{McCrae}^{84}$. The ZKPQ has measures of Emotionality 
Table 4 Correlations $(r \times 100)$ in adults between TCI Scales and proposed measures of temperament or heritable personality dimensions derived by linear factor analysis

Scales of Temperament and Character Inventory

\begin{tabular}{|c|c|c|c|c|c|c|c|}
\hline Other inventories ${ }^{a}$ & HA & NS & RD & PS & SD & $\mathrm{CO}$ & ST \\
\hline \multicolumn{8}{|l|}{ ATQ } \\
\hline $\begin{array}{l}\text { Non-aggressive } \\
\text { negative affect }\end{array}$ & 60 & & & & -51 & -24 & \\
\hline Aggressive negative affect & 39 & & & & -47 & -49 & \\
\hline Extraversion & -38 & 28 & 57 & 21 & 28 & 38 & 32 \\
\hline Orienting sensitivity & & 30 & & & & 2 & 31 \\
\hline Affiliativeness & & & 47 & & & 52 & 29 \\
\hline Effortful control & -37 & & & 43 & 41 & & \\
\hline \multicolumn{8}{|l|}{$Z K P Q$} \\
\hline Neuroticism & 66 & & & & -49 & & \\
\hline Impulsive sensation seeking & -39 & 68 & -20 & & & & 28 \\
\hline Hostility & & & -27 & & -32 & -60 & \\
\hline Sociability & -38 & 37 & 31 & & & & \\
\hline Activity & -29 & & & 46 & 36 & & \\
\hline \multicolumn{8}{|l|}{ EAS-TS } \\
\hline Negative emotionality & 57 & & & & -53 & -30 & \\
\hline Activity & -31 & & & 29 & & & \\
\hline Sociability & -25 & & 45 & & & 30 & \\
\hline \multicolumn{8}{|l|}{$E P Q-R$} \\
\hline Neuroticism & 59 & & & & -45 & & \\
\hline Extraversion & -53 & 44 & 23 & & & & \\
\hline Psychoticism & & 41 & -45 & -29 & -31 & -42 & \\
\hline \multicolumn{8}{|l|}{ NEO-PI-R } \\
\hline Neuroticism & 63 & & & -20 & -62 & & \\
\hline Extraversion & -55 & 40 & 52 & 40 & 25 & & 22 \\
\hline Openness & -25 & 43 & 25 & & & & 37 \\
\hline Conscience & -26 & -34 & & 51 & 41 & & \\
\hline Agreeability & & -23 & 40 & & & 61 & 20 \\
\hline
\end{tabular}

Correlations over 0.4 in bold and other significant correlations over 0.2 shown ${ }^{a}$ Other inventories are Adult Temperament Scale (ATQ) ${ }^{82}$, Zuckerman-Kuhlman Personality Questionnaire (ZKPQ) ${ }^{83}$, Emotionality-Activity-Sociability Temperament Survey (EAS-TS) ${ }^{29}$, Eysenck Personality Questionnaire (EPQ-R) ${ }^{83}$, and Revised NEO Personality Inventory (NEO-PI-R) ${ }^{84}$

(Neuroticism), Activity, Sociability, and Impulsive Sensation Seeking, so it is the alternative five-factor model for adults that is most similar in structure to the EAS and EASI temperament models for children and adults (see Table 4). These adult inventories also include selfregulatory components of personality with moderate to strong correlations with character traits of Selfdirectedness and Cooperativeness, such as ATQ effortful control, NEO agreeability/ATQ affiliativeness versus ZKPQ hostility, and NEO conscientiousness. Just as was observed with TCI temperaments in early childhood (Table 3), TCI temperaments in adulthood are closely related to other measures of adult personality traits, with correlations between 0.5 and 0.7: Harm Avoidance with measures of Neuroticism/Emotionality, Novelty Seeking with Impulsivity, Reward Dependence with Sociability/ Affiliation/Extraversion, and Persistence with Activity/ Conscientiousness. Although these relations are moderate to strong and indicate pervasive overlap in the overall content of different tests of temperament and personality, there are no simple one-to-one relations among the different tests, as can be seen in Tables 2-4 regardless of the number and content of factors or the age of subjects.

In summary, TCI temperaments are differentially associated with other specific temperament scales using a variety of inventories based on a variety of characteristics, including the formal characteristics of behavior, onset in early childhood, developmental stability, and/or a heritable and neurobiological basis. However, these traditional criteria have not enabled investigators to specify the structure and content of temperament in a way that is discrete and distinct from other aspects of personality. The architecture of temperament and personality does not have the linear structure that is unrealistically assumed by linear factor analysis and classical psychometric test theory: there are significant relations among multiple components of one test with multiple components of other tests, rather than simple one-to-one relations between components of tests that focus on different characteristics (e.g., on formal energetic and temporal characteristics, on developmental stability, or heritability) regardless of age (Tables 2-4).

As a result of the complex internal structure of multiscale temperament and personality inventories, most widely used inventories with documented evidence of criterion-related validity perform poorly when their structure is evaluated by confirmatory factor analysis ${ }^{85,86}$. Even in adulthood, development is complex and nonlinear with substantial evidence of both multi-finality and equi-finality, as is expected for the behavior of non-linear dynamical systems involving learning to adapt to everchanging conditions ${ }^{14,25-27,87}$.

Both automatic and self-regulatory aspects of personality are heritable ${ }^{41,88}$ and some self-regulatory aspects of personality begin to develop in early childhood ${ }^{19}$. Consequently more fundamental features of temperament than heritability and early appearance are needed to distinguish temperament from other aspects of personality. Therefore we will now discuss new molecular findings about the qualitative differences in systems of learning 
that have emerged at different stages in the evolutionary line of ancestors of modern human beings ${ }^{4,27,42,89}$ and that may distinguish temperament from other personality traits in a fundamental way that satisfies all the traditional concepts $^{25-27,90}$.

\section{Dispositions in habit learning as the fundamental basis of temperament}

The temperament scales of the TCI were developed to measure specific constructs of associative conditioning based on data about the genetic structure of human personality in twins, phenotypic structure of habit learning by associative conditioning in humans and experimental animals, and the evolution of neurobiological mechanisms by which animals learn to adapt to changing conditions in their environment ${ }^{91-94}$. Initially the model was limited to temperament traits only, but has always included subscales to measure how broad dispositions are expressed in different situations ${ }^{92}$, as shown in Supplementary Table 2. Later observations revealed that people with any temperament profile could be healthy or unhealthy depending on character traits of Self-directedness, Cooperativeness, and Self-Transcendence, that were initially described on the basis of concepts from humanistic and transpersonal psychology ${ }^{6,13,56}$. We also found that temperament and character were equally heritable ${ }^{41}$, and hypothesized that they were distinguished by the distinct properties of brain networks that were equally heritable but involved in dissociable forms of learning and memory that had emerged at different times in the long evolutionary history of human beings: associative conditioning (i.e., classical and operant conditioning), Intentionality (i.e., self-directed and purposeful goal-seeking and cooperative behavior for mutual benefit), and Selfawareness (i.e., transpersonal or self-transcendent behaviors including creative imagination, mental time-travel, theoretical reasoning, and appraisal of values from a transpersonal perspective) $)^{25-27,42,95-97}$. Comparative analysis of neuroanatomy and emergent cognitive-behavioral functions in the ancestors of human beings suggested that temperament involved associative conditioning, which is highly conserved in all animals ${ }^{42}$. In contrast, brain functions for intentional self-regulation only emerged in higher primates, and self-awareness with creative capacities for art, science, and spirituality is present only in modern human beings ${ }^{42,45,89,95,98}$. These three brain networks normally interact in a coordinated manner ${ }^{99-101}$, but they are dissociable developmentally ${ }^{45,46,102}$ and functionally ${ }^{45,100,101,103-106}$.

A major limitation of earlier model-driven approaches to constructing temperament and personality inventories has been the tendency of people to fit their data to questionable assumptions of classical test theory using linear factor analysis. As we have just described in the prior section, the approach of fitting data to models has resulted in the failure to produce a consensus about how to measure temperament or how to distinguish it from other aspects of personality because people begin and end with different theories. Likewise, the tendency to fit genotypic data to models with the assumption that genes act independently of one another in the development of complex phenotypes like temperament and character is unrealistic because there is strong evidence of extensive gene-gene interaction for these traits ${ }^{107}$. In fact, prior estimates of gene-gene interaction in family studies of twins account for $\sim 50 \%$ of the broad heritability of a variety of personality traits, with a range of $25-77 \%{ }^{108-112}$, as summarized in Supplementary Table 5.

The model-driven approach to genome-wide association studies has failed to uncover the genotypicphenotypic structure of complex traits and left most variability in complex traits unexplained by observed genotypes ${ }^{107}$. Instead of the estimates of $50 \%$ heritability of personality expected from twin studies, the heritability explained by SNPs has usually been $\sim 10 \%$, with a range of $0-21 \%^{113-123}$, as summarized in Supplementary Table 6. Therefore, we sought a data-driven method to test theories by fitting models to the data without restrictive and arbitrary theoretical assumptions.

We used a data-driven method called PhenotypeGenotype Many-to-many Relations Analysis (PGMRA) to identify SNPs that map to 972 genes that explained nearly all the variability in both temperament and character expected from twin studies in three independent samples of Finns, Germans, and Koreans ${ }^{25-27}$. Our machine learning approach ${ }^{124,125}$ uses the Non-Negative Matrix Factorization (NMF) method, which identifies multidimensional patterns within different types of data, such as quantitative or categorical phenotypes, genotypes, environmental variables, and/or voxels of neuroimages ${ }^{25-}$ $27,126-128$. To uncover the natural genotypic-phenotypic architecture of a complex trait like temperament, PGMRA first dissects genome-wide data and uncovers a genotypic architecture composed of sets of SNPs shared by subsets of individuals (i.e., SNP sets), thereby allowing for complex genotypic information (such as gene-gene interaction and linkage disequilibrium) independent of any information about the phenotype. Next, phenotypic data are independently organized into natural sets of features, such as configurations of temperament traits shared by subsets of individuals (i.e., phenotypic sets); this allows for complex phenotypic interactions, such as heterogeneous temperament profiles, independent of any information about the genotype. Cross-matching of the two types of sets reveals multiple associations restricted to subgroups of individuals, thereby allowing for complex developmental phenomena, such as multi-finality and equifinality. Other variable domains can also be integrated 
into the analysis, such as parental rearing, cultural influences, and other environmental exposures with or without measuring genotypes. The data-driven algorithm functions to extract and organize as much information as is available to increase the study power, so that moderately sized samples of people who are thoroughly assessed can be well powered ${ }^{107,128}$.

Our discovery sample was the Young Finns Study, an epidemiological study of 2149 healthy Finnish children followed regularly from 1980 (ages 3-18 years) to 2012 (ages 35-50) ${ }^{129}$. All subjects had thorough standardized genotypic, environmental, and phenotypic assessments, including administration of the Temperament and Character Inventory (TCI) in 1997, 2001, 2007, and $2012^{8,129}$. We replicated the results in two independent samples of 902 healthy adults from Germany ${ }^{130}$ and 1052 from Korea ${ }^{131,132}$ in which comparable genotypic and phenotypic features were available ${ }^{25,26}$. PGMRA was used to uncover the complex genotypic-phenotypic associations in the two replication samples (Germans and Koreans) independent of information about the discovery sample. The process used in the discovery sample was blindly and independently repeated in each replication sample without assuming homogeneity within or across samples ${ }^{107}$. We accounted for ethnicity in each sample by using the first three principal components for ancestral stratification of SNP genotypes ${ }^{25,26}$. Then matching of genotypic-phenotypic associations across samples was identified using parsimonious models that balance accuracy with model complexity, thereby avoiding overfitting ${ }^{133}$. Models were learned independently in diverse samples to provide a stringent test of reproducibility despite complexity that might result from possible genetic, ethnic, cultural and environmental heterogeneity ${ }^{107}$.

We identified three clusters of people using the TCI temperament scales that measure individual differences in associative conditioning, behavioral activity, and emotional reactivity ${ }^{26}$. The three clusters corresponded closely to temperament clusters described by Thomas and Chess as "easy", "difficult", and "slow to warm-up" "76,77. People in our "reliable" cluster resembled children with an "easy temperament" and adults who were conscientious extraverts because they were well-controlled in activity and were warm and calm emotionally. In other words, they were high in Reward Dependence (i.e., sentimental, friendly, approval-seeking), low in Novelty Seeking (i.e., deliberate, thrifty, orderly), low in Harm Avoidance (i.e., optimistic, confident, outgoing, and vigorous), and high in Persistence (i.e., determined). People in our "sensitive" temperament cluster resembled children with a "difficult temperament" and adults who are neurotic and unstable because they were under-controlled in activity and emotionally hypersensitive. Put another way, they were high in
Harm Avoidance (i.e., pessimistic, fearful, shy, and fatigable), high in Novelty Seeking (i.e., impulsive, extravagant), and high in Reward Dependence (i.e., sentimental, friendly), so they frequently had approachavoidance conflicts, rejection sensitivity, and disorganized attachments. People in our "antisocial" temperament cluster resembled children with a "slow to warm" temperament and adults who are socially detached, careless, and impulsive. That is, they were low in Reward Dependence (i.e., cold, detached, independent), low in Persistence (i.e., easily discouraged), and high in Novelty Seeking (i.e., extravagant, rule-breaking, but not inquisitive), which is frequently associated with maladaptive antisocial conduct.

We found 51 SNP sets that mapped to 736 gene loci and were significantly associated with one or more of the temperament sets. The neuronal functions and molecular processes associated with particular SNP sets and temperament profiles are shown in Table 5. Seventy-four percent of the identified genes were unique to a specific temperament profile, but 20 of the 51 SNP sets show substantial multi-finality (pleiotropy) in which at least $25 \%$ of carriers of the SNP set have different temperament profiles (Table 5). Such detailed data about the genotypic-phenotypic relations of temperament clusters are only available using the TCI. However, to facilitate consideration by readers familiar with other tests and to guide future investigation, the replicated TCI findings can be tentatively translated into profiles using scales measured by eight other major models of temperament and personality for which the relations with the TCI are known (see Supplementary Table S7). The genotypic sets distinguish people with distinct temperament profiles, so different descriptive models are hypothesized to capture the same clusters from various perspectives based on their correlations with the TCI: most traits in each system are at least moderately correlated with one or more TCI temperaments that differentiate the associated genotypic clusters.

Put another way, the different models that have been developed for measuring temperament are like dialects of a common language with inconsistent accretions from their variable integration with character traits during development. The inconsistencies between these dialects are minimized when they are restricted to the multidimensional configurations that are associated with the common genotypic language of temperament. For example, each model of temperament identifies highly Harm Avoidant people as neurotic introverts (i.e., people who are high in Neuroticism, Negative Emotionality, or Emotional Reactivity) and low in Extraversion. However, Extraversion (i.e., positive emotionality) is a complex composite of low Harm Avoidance, high Novelty Seeking, high Reward Dependence, and some contributions from 
Table 5 Neuronal functions and molecular processes associated with particular SNP sets and temperament profiles, including reliable (R), sensitive (S), and antisocial (A) profiles, and numbers of subjects and of genes mapped to each SNP set

\begin{tabular}{|c|c|c|c|c|c|}
\hline Neuronal functions & SNP set & SNP set name & genes $n$ & subjects $n$ & Temperament profiles \\
\hline \multirow[t]{5}{*}{ Neuroplasticity } & G_28_15 & Estrogen neuroplasticity & 29 & 101 & $\mathrm{~S}$ or $\mathrm{A}$ \\
\hline & G_41_33 & GPCR neuroplasticity & 15 & 56 & S \\
\hline & G_28_10 & WD/CDK neuroplasticity & 8 & 46 & $\mathrm{R}$ \\
\hline & G_38_23 & Sensory sensitivity & 16 & 39 & $\mathrm{~S}$ \\
\hline & G_30_28 & Hippocampal synaptic plasticity & 10 & 34 & $\mathrm{~S}$ \\
\hline \multirow[t]{4}{*}{ Long-term memory } & G_12_1 & Episodic memory & 66 & 146 & $\mathrm{R}$ \\
\hline & G_7_3 & Neurogenesis & 128 & 133 & $\mathrm{~S}$ or $\mathrm{A}$ \\
\hline & G_12_11 & Ras-AKT interaction & 4 & 105 & $R, S$, or $A$ \\
\hline & G_31_8 & Neurotrophin & 60 & 54 & $\mathrm{~S}$ or $\mathrm{A}$ \\
\hline \multirow[t]{3}{*}{ Energy production } & G_26_14 & Glucose transport & 25 & 46 & $\mathrm{~S}$ or $\mathrm{A}$ \\
\hline & G_25_20 & Fatty acid oxidation & 3 & 33 & $\mathrm{R}$ \\
\hline & G_36_29 & Electron transport & 49 & 25 & $S$ \\
\hline \multirow[t]{3}{*}{ Cognitive flexibility } & G_21_18 & Cognitive flexibility & 15 & 116 & $\mathrm{R}$ or $\mathrm{A}$ \\
\hline & G_38_17 & MAPK memory enhancement & 13 & 14 & $\mathrm{R}$ \\
\hline & G_5_3 & Regulation pathways & 2 & 172 & $\mathrm{R}$ \\
\hline \multirow[t]{8}{*}{ Resistance to stress, injury, \& aging } & G_8_8 & Global inositol/chemokine pathways & 286 & 224 & $\mathrm{R}$ \\
\hline & G_12_8 & Neuroprotection & 111 & 173 & $R, A$, or $S$ \\
\hline & G_16_15 & Interleukin-2 neuroimmune response & 7 & 94 & A \\
\hline & G_21_17 & TGF $\beta$ resistance to aging & 26 & 67 & $\mathrm{R}$ \\
\hline & G_33_33 & TGF $\beta$ memory enhancement & 13 & 49 & $\mathrm{R}$ \\
\hline & G_30_10 & TNF-based resilience & 6 & 47 & $\mathrm{R}$ \\
\hline & G_37_6 & Methylation-based gene silencing & 23 & 26 & $\mathrm{R}$ \\
\hline & G_20_2 & Enhanced memory & 18 & 25 & $\mathrm{R}$ \\
\hline \multirow[t]{4}{*}{ Cholinergic neuromodulation } & G_13_10 & Cholinergic neuromodulation & 17 & 148 & $\mathrm{R}$ \\
\hline & G_13_12 & Acetylcholine biosynthesis & 1 & 78 & $\mathrm{~S}$ or $\mathrm{R}$ \\
\hline & G_21_16 & Acetylcholine biosynthesis & 1 & 37 & $\mathrm{~S}$ or $\mathrm{A}$ \\
\hline & G_25_3 & Acetylcholine biosynthesis & 2 & 16 & $\mathrm{~S}$ or $\mathrm{A}$ \\
\hline \multirow[t]{3}{*}{ Fear conditioning } & G_30_9 & ERK-IP3-PKC stress interaction & 52 & 69 & S \\
\hline & G_39_21 & RGS negative emotionality & 5 & 56 & $S$ \\
\hline & G_41_37 & PI3K-MAPK cognitive function & 11 & 41 & $\mathrm{~S}$ \\
\hline \multirow[t]{8}{*}{ Stress reactivity } & G_7_2 & GPCR dysregulation & 147 & 211 & $\mathrm{~S}$ or $\mathrm{A}$ \\
\hline & G_9_2 & Serotonin-cytokine interaction & 11 & 140 & $\mathrm{~S}$ or $\mathrm{A}$ \\
\hline & G_16_5 & ERK-IP3-PKC stress memory & 1 & 87 & $\mathrm{R}$ \\
\hline & G_14_12 & Ras-based stress memory & 22 & 83 & A \\
\hline & G_21_3 & cellular senescence & 39 & 60 & $\mathrm{~S}$ or $\mathrm{A}$ \\
\hline & G_11_7 & HPA stress reactivity & 11 & 26 & $\mathrm{~S}$ or $\mathrm{A}$ \\
\hline & G_33_4 & ERK-PKA interaction & 6 & 24 & $\mathrm{~S}$ or $\mathrm{A}$ \\
\hline & G_38_38 & Ion permeability & 18 & 38 & S \\
\hline
\end{tabular}


Table 5 continued

\begin{tabular}{|c|c|c|c|c|c|}
\hline Neuronal functions & SNP set & SNP set name & genes $n$ & subjects $n$ & Temperament profiles \\
\hline & G_22_6 & Blood-brain barrier permeability & 30 & 37 & $\mathrm{~S}$ or $\mathrm{A}$ \\
\hline & G_42_39 & Approach-avoidance conflict & 11 & 19 & S \\
\hline \multirow[t]{3}{*}{ Conditioning of dopaminergic activation } & G_16_1 & PI3K-based memory & 11 & 108 & A \\
\hline & G_35_22 & PI3K-based memory & 5 & 43 & $\mathrm{~S}$ or $\mathrm{A}$ \\
\hline & G_39_26 & mTOR myelination & 26 & 20 & $\mathrm{~S}$ or $\mathrm{A}$ \\
\hline \multirow[t]{5}{*}{ Conditioning of neuroexcitability } & G_7_7 & Olfaction & 58 & 145 & A \\
\hline & G_13_3 & ERK-conditioned impulsivity & 21 & 95 & $\mathrm{~S}$ or $\mathrm{A}$ \\
\hline & G_35_7 & PI3K-based memory & 12 & 32 & A \\
\hline & G_37_14 & Neuroexcitability & 12 & 21 & A \\
\hline & G_36_18 & Brain RNA biosynthesis & 4 & 19 & A \\
\hline \multirow[t]{3}{*}{ Habit extinction } & G_38_13 & Glucuronidase habit extinction & 7 & 60 & $R, A$, or $S$ \\
\hline & G_19_3 & Glucuronidase habit extinction & 5 & 48 & $S$ \\
\hline & G_40_5 & Mannosidase habit extinction & 3 & 16 & A \\
\hline
\end{tabular}

Adapted from Zwir et al. ${ }^{25}$, Tables 1 and 3

$73.6 \%$ of the 736 genes associated with temperament were unique to a single temperament profile: 266 with reliable, 236 with sensitive, and 40 with antisocial

character traits (Tables 2 and 3). Consequently, Extraversion can indicate any of these TCI traits depending on its configurations with low Neuroticism (indicating low Harm Avoidance), high Impulsivity (indicating high Novelty Seeking), and/or high Sociability (indicating high Reward Dependence). Different inventories measure what they call high Activity in qualitatively different ways: it may involves extraverted social activity (i.e., high Reward Dependence, as in the Strelau FCB inventory), persistent and enduring activity (i.e., high Persistence, as in the ZKPQ or the Strelau FCB Inventory), or restless motor behavior, as in the EAS or CCTI, which is not consistently associated with TCI temperaments (see Tables 2 and 3). Like restless motor activity, TCI character traits are variably associated with $\mathrm{TCI}$ temperaments, as are ZKPQ Hostility and NEO Agreeability. Rothbart's CBQ effortful control and NEO conscientiousness are composites of high TCI Persistence plus the self-regulatory character trait measured by high Self-directedness in the TCI. There is certainly loss of specificity for genotypic associations with such heterogeneous measures, but the multidimensional profiles should provide a useful tool for investigators without access to genotypic data about their own model, or for investigators to test the robustness of our genotypic findings with other models. We hope this information will also encourage more work with both individual dimensions and multidimensional profiles, which have complementary utility.

What then is the common genotypic language of temperament? Most of the identified genes were enriched in pathways activated by associative conditioning in animals, including the ERK, PI3K, and related protein kinase pathways, which are highly conserved in all animals (Fig. 2). When activated, the Ras-MEK-ERK cascade (also known as the mitogen-activated protein kinase (MAPK) pathway) and the PI3K-AKT-mTOR cascade serve as the major cellular mechanisms for response to extracellular stimuli, including activation of processes that promote synaptic plasticity, associative conditioning, and longterm memory ${ }^{134-138}$. The cell-surface receptors for these pathways can be activated by a wide variety of physiological, psychosocial, and energetic stimuli that vary in positive and negative valence and in consequences for health and survival ${ }^{136,139,140}$. Changes in these pathways in response to associative conditioning occur in a coordinated manner with related processes including stress reactivity ${ }^{141}$, neuronal and glial growth ${ }^{142}$, and neurotransmission $^{143}$. Both pathways converge on mTOR, which allows modulation of their joint action and circadian rhythmicity (Fig. 2) 26,144,145.

In summary, our findings suggest that individual differences in associative conditioning (habit learning, including classical and operant conditioning) may be the fundamental molecular mechanism for human temperament. Individual differences in associative conditioning provides a precise definition and causal mechanism that accounts for all the traditional concepts about temperament being distinguished from other aspects of personality by its formal behavioral style (how we learn) and emotional reactivity, which correspond to response patterns that are highly conserved in all animals, present in people from early childhood, and moderately stable across the life span. 


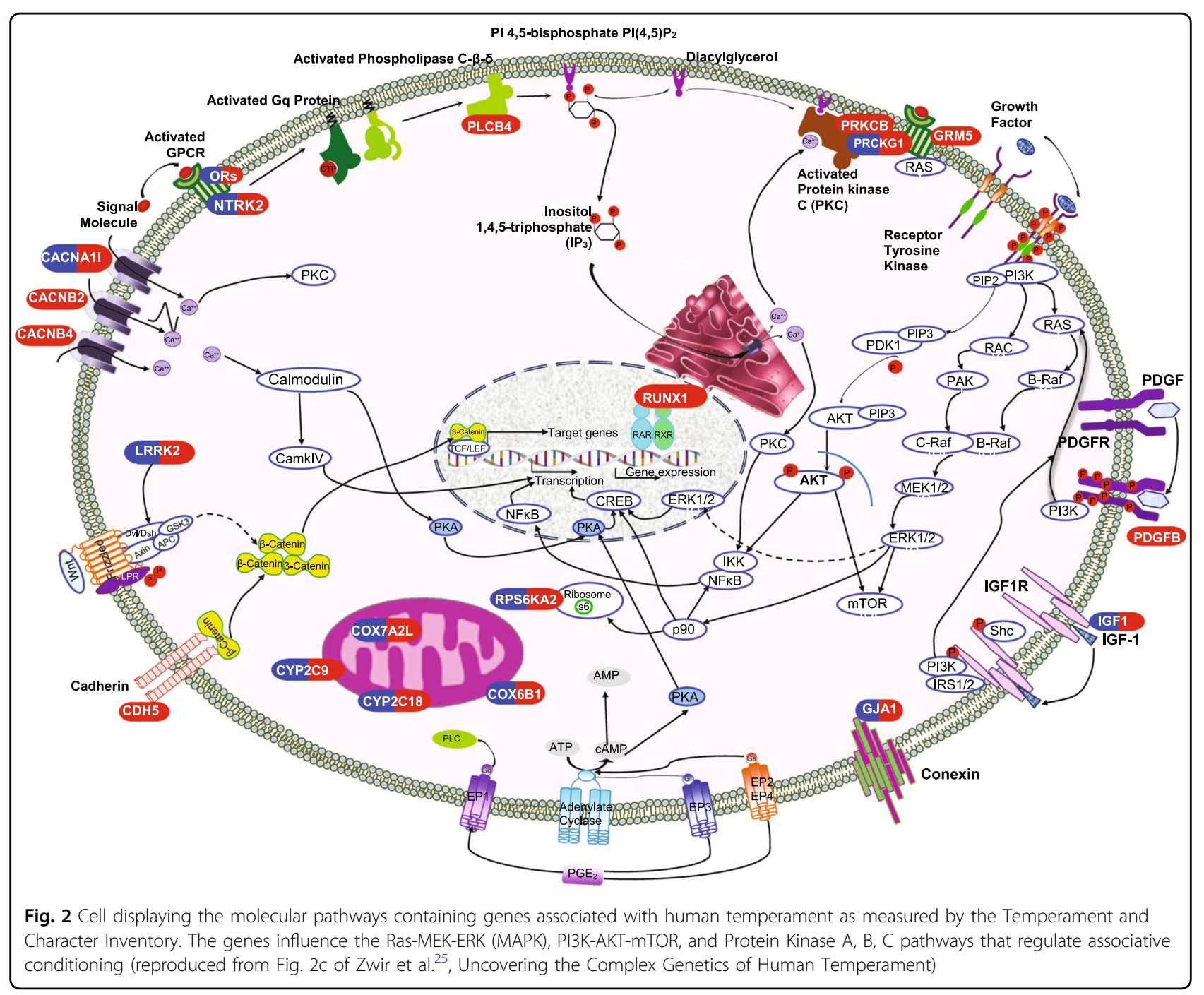

However, these findings also open up many more questions for future study by investigators with diverse interests and skills. Temperament researchers have varied in whether they focused on individual traits or subtypes defined by profiles of multiple traits. We found that most of the genes for each associated with each temperament subtype were unique to that subtype, which suggests that the natural unit of measurement of temperament are profiles of multiple traits within an individual, not single traits that differ between individuals ${ }^{90}$. Nevertheless, activation of the genotypic sets leads to different behavioral responses in response to different environmental challenges, so this needs to be considered, as we begin to describe in the next section. The same person can carry multiple genotypic sets, so their individual traits may be a mixture of the effects of these multiple genotypic sets, as we have described elsewhere ${ }^{25,26}$ along with vignettes of the pure prototypes ${ }^{27}$. In addition, environmental influences during development can influence the development of temperament substantially by influences on the way the antecedents of temperament and character become integrated and self-actualized, as we have also begun to explore $^{27}$. Identifying the fundamental molecular mechanisms underlying temperament is expected to help move its investigation forward in a more integrated way, and opens up many opportunities for translational research and practice. We will illustrate some basic questions that need more thorough study by available results regarding stimuli that allowed observers to recognize the distinguishing features of temperament in antiquity and that may still guide us in developing interventions to facilitate the healthy functioning of people by understanding their temperament.

\section{Psychobiological modulation of temperament- related molecular pathways}

Observations of temperament provide a direct window by which we can observe the powerful mechanisms that 
evolved in animals to allow rapid and effective adaptations to extracellular stimuli that are essential for the health and survival of all animals. Temperaments evolved in ways that help animals to adapt to naturally occurring variation in external and internal stimuli, which is essential for cellular proliferation and plasticity, resistance to degenerative processes (related to stress, injury, and aging), regulation of immune and inflammatory response, and maintenance of energy production, in addition to processes that mediate habit learning, emotional reactivity, cognitive flexibility, sensory sensitivity, and circadian rhythmicity, as shown for the functions of temperamentrelated SNP sets in Table $5^{26,146-148}$. Consequently the molecular mechanisms underlying temperament may play important roles in susceptibility to the common diseases that burden modern society as a result of direct expression in particular organs and as a result of indirect influences mediated by lifestyle behaviors ${ }^{26,147-153}$.

The effects of key physiological and energetic extracellular stimuli on the Ras-MEK-ERK and PI3K-AKTmTOR cascades related to temperament are summarized in Table 6. These stimuli are important regulators of adaptive responses to diurnal, seasonal, and climactic variation in conditions that require automatic adaptation in order to maintain cellular homeostasis, healthy functioning, and repair mechanisms. These stimuli correspond to changing diurnal and seasonal conditions to which animals must adapt for their health, reproduction, and survival despite changes between hot and cold temperatures $^{154-158}$, light and dark luminosity ${ }^{145,159,160}$, and other conditions including exposure to electromagnetic fields ${ }^{161-168}$, variable supplies of water ${ }^{169-172}$ and nutrients ${ }^{172}$, and variable demands for physical activity ${ }^{173-175}$ and opportunities for sleep ${ }^{176-178}$. Under experimental or natural conditions, diurnal and seasonal rhythmicity in activity is associated with individual differences in TCI temperaments: people who are high in Novelty Seeking prefer to be more active late at night rather than in the morning ${ }^{179-181}$ and are more likely to have been born during the long photoperiod of summer than the short photoperiod of winter ${ }^{181,182}$. Furthermore, diurnal rhythms in activity are associated with seasonal rhythms in activity, emotionality, sociability, and body temperature $^{180}$, much like the descriptions of distinguishing features of the classical temperament subtypes (Supplementary Table 1).

\section{Translating the new genetics of temperament for research and practice}

The first and major implication of the new genetic findings is a precise definition of temperament, which is really a fundamental need for good communication and incremental research progress within any scientific field. Based on the findings reviewed here, we propose the following definition: Temperament is the disposition of a person to learn how to behave, react emotionally, and form attachments automatically by associative conditioning (that is, rapidly and spontaneously, without conscious attention or reflection in response to changing internal and external conditions). Each part of the definition outside the explanation in parenthesis is essential: (1) temperament is the organization within an individual (i.e., a disposition, or set of distinguishing features) of how a person learns, not what, when, where, or why they learn; it involves the form and style of how a person learns; (2) the characteristic features involve what can be learned by associative conditioning, which include habitual patterns of behavior, emotional reactions, and attachments; (3) learning by associative conditioning in response to changing conditions is automatic and spontaneous (that is, without delay for conscious attention or reflection).

We propose that these criteria are necessary and sufficient to define temperament precisely. Our proposed definition is sufficient because it implies all the traditional criteria proposed for temperament, and it is necessary because the other criteria are non-specific when used individually or in combination. From this basic definition, it follows that the predisposition to temperament is innate and heritable, but its expression may change in response to associative conditioning, which can be modified by brain development or injury and by its integration with other systems of learning and memory related to other aspects of personality involving self-regulatory processes for intentional self-control and creative self-awareness. Associative conditioning is highly conserved in all animals, whereas intentional self-control emerged only in higher primates and self-awareness in human beings ${ }^{25-27}$. The integration of these systems is manifest in the complex and dynamic patterns of development that are observed for personality, language, art, and science across the life span of a person in response to changing conditions $^{27}$.

We suggest that the proposed definition of temperament captures all the traditional concepts with specificity and precision, distinguishing it from other aspects of personality with which it becomes integrated during development. For example, a temperament can be unambiguously distinguished by heritable differences in behavioral conditioning; what is inherited as temperament is limited to the habit learning system, the component of procedural learning that is evolutionarily conserved in all animals. Cognitive systems for intentional self-control that emerged in higher primates may begin to interact with temperament from an early age ${ }^{19}$, but they involve fundamentally distinct molecular processes and brain structures than does temperament ${ }^{42,43}$. This definition yields the expected features of appearance in early childhood, prominence of basic emotions and automatic 
Table 6 Effects of physiological and energetic extracellular stimuli on temperament-related Ras-ERK (MAPK) and PI3KAKT-mTOR pathways

\begin{tabular}{|c|c|c|c|c|}
\hline Extracellular stimulus & $\begin{array}{l}\text { Effect on Ras- } \\
\text { ERK }\end{array}$ & Effect on PI3K-AKT-mTOR & Cellular response & References \\
\hline \multicolumn{5}{|l|}{ Temperature } \\
\hline Cold & Inhibition & & $\begin{array}{l}\text { Quiescence (cold slows growth and metabolism, } \\
\text { promotes repair of injury, reduces pain and } \\
\text { inflammation) }\end{array}$ & $\begin{array}{l}\text { Hypothermic stress } \\
\text { repair of injury }\end{array}$ \\
\hline Hot & & Activation & $\begin{array}{l}\text { Growth and proliferation (heat increases growth and } \\
\text { switches cells from catabolic to anabolic processes) }\end{array}$ & $\begin{array}{l}\text { Heat stress } \\
\text { anabolic switch }^{158}\end{array}$ \\
\hline \multicolumn{5}{|l|}{ Luminosity (visible light) } \\
\hline Dark & & Inhibition & Slows and dampens circadian rhythmicity via mTOR & Night ${ }^{145}$ \\
\hline Bright & Activation & Activation & $\begin{array}{l}\text { Accelerates and enhances circadian rhythmicity via } \\
\text { mTOR, directs neurite outgrowth via Ras-ERK }\end{array}$ & Visible light pulses ${ }^{145,159,160}$ \\
\hline \multicolumn{5}{|l|}{ Electromagnetic fields } \\
\hline $\begin{array}{l}\text { External high frequency } \\
\text { (not protected) }\end{array}$ & Inhibition & Inhibition & $\begin{array}{l}\text { Exposure to non-thermal high-frequency EMF impairs } \\
\text { hippocampus function, emotional stability, passive- } \\
\text { avoidance learning, and regulation of impulse-control } \\
\text { via inhibited Ras-Erk, and inhibited AKT and voltage- } \\
\text { gated calcium channel signaling of self-control }\end{array}$ & $\begin{array}{l}\text { External non-thermal } \\
\text { GHz EMF exposure }\end{array}$ \\
\hline $\begin{array}{l}\text { External high frequency } \\
\text { (protected) }\end{array}$ & & & $\begin{array}{l}\text { Administration of melatonin and omega- } 3 \text { fatty acids } \\
\text { protects against the harmful effects of non-thermal } \\
\text { high-frequency EMF }\end{array}$ & $\begin{array}{l}\text { Neuroprotection from } \\
\text { non-thermal EMF }\end{array}$ \\
\hline $\begin{array}{l}\text { Low-intensity and low- } \\
\text { frequency EMF }\end{array}$ & $\begin{array}{l}\text { Inhibition or } \\
\text { activation }\end{array}$ & & $\begin{array}{l}\text { Exposure to low-intensity, frequency-modulated EMF } \\
\text { can inhibit or activate depending on frequency, site, and } \\
\text { temperament. } 24 \mathrm{HZ} \text { EMF inhibits cell proliferation by } \\
\text { inhibiting Ras-ERK (MAPK) pathways. In contrast, } 10 \mathrm{HZ} \\
\text { transcranial magnetic stimulation of dorsolateral PFC } \\
\text { reduces negative affect in ways related to temperament } \\
\text { and ERK pathway (uncoupling subgenual ACC from } \\
\text { default mode network is reduced by higher Harm } \\
\text { Avoidance, and increased by higher Persistence). Anti- } \\
\text { depressant effects involve activation of Ras-Erk with } \\
\text { proliferation of hippocampal-derived neural stem cells) }\end{array}$ & $\begin{array}{l}\text { Frequency-modulated } \\
10-25 \text { HZ EMF } \\
\text { exposure }\end{array}$ \\
\hline \multicolumn{5}{|l|}{ Hydration } \\
\hline Dry & Inhibition & & $\begin{array}{l}\text { Dehydration inhibits components like AMPK and TSC } \\
\text { around mTOR signaling, thereby reducing cellular } \\
\text { energy from glucose intake, glycogen synthesis, } \\
\text { lipogenesis, and ERK expression }\end{array}$ & $\begin{array}{l}\text { Hyper-osmotic } \\
\text { dehydration }^{169,170}\end{array}$ \\
\hline Wet & Activation & & $\begin{array}{l}\text { Hydration promotes Ras-ERK and mTOR signaling, } \\
\text { increasing cellular energy availability }\end{array}$ & $\begin{array}{l}\text { Hypo-osmotic } \\
\text { hydration }\end{array}$ \\
\hline \multicolumn{5}{|l|}{ Nutrition } \\
\hline Fasting & & $\begin{array}{l}\text { Inhibition by nutrient and } \\
\text { energy depletion }\end{array}$ & $\begin{array}{l}\text { The mTOR complex depends on nutrient availability so } \\
\text { its activity is reduced by diverse mechanisms of energy } \\
\text { depletion }\end{array}$ & $\begin{array}{l}\text { Nutrient sensing by } \\
\text { mTOR }^{172}\end{array}$ \\
\hline Feeding & & $\begin{array}{l}\text { Activation by various } \\
\text { nutrients, particularly } \\
\text { amino-acids, insulin-and } \\
\text { growth-factor signaling }\end{array}$ & & $\begin{array}{l}\text { Nutrient sensing by } \\
\text { mTOR }^{172}\end{array}$ \\
\hline \multicolumn{5}{|l|}{ Exercise } \\
\hline Inactive & Low activity & Low activity & & \\
\hline Active & Activation & Activation & $\begin{array}{l}\text { Exercise activates both ERK and mTOR signaling via } \\
\text { increased expression of AMPK, CAMK4, and p38 genes, } \\
\text { leading to increased cellular growth, energy availability } \\
\text { from mitochondrial biogenesis in multiple body tissues, } \\
\text { including neurons and muscle, and increased } \\
\text { morphological plasticity of muscle and increased insulin } \\
\text { sensitivity in diabetes and obesity. }\end{array}$ & Endurance training ${ }^{173-175}$ \\
\hline \multicolumn{5}{|c|}{ 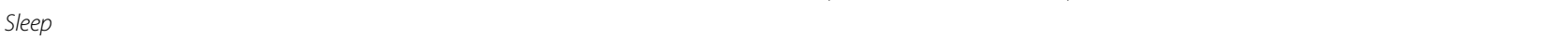 } \\
\hline Deprived & Inhibition & & $\begin{array}{l}\text { Sleep deprivation reduces expression of Ras-ERK } \\
\text { pathway, leading to impaired learning and memory, as } \\
\text { observed in parasomnias associated with increased } \\
\text { Novelty Seeking }\end{array}$ & Sleep deprivation ${ }^{176,177}$ \\
\hline Unlimited & Activation & & $\begin{array}{l}\text { Duration of sleep is regulated by ERK pathway by effects } \\
\text { on expression of activity-dependent neuromodulators } \\
\text { like norepinephrine during wakefulness }\end{array}$ & $\begin{array}{l}\text { Modulation of sleep and } \\
\text { wakefulness }^{178}\end{array}$ \\
\hline
\end{tabular}


behaviors, and moderate stability over time, which also distinguish temperament from other aspects of personality, as summarized in Table 1.

An alternative definition is that "temperament refers to neurochemically based individual differences in the regulation of formal dynamical aspects of behavior ${ }^{22}$." Reference to the formal dynamical aspects of behavior, as did Strelau (see Table 2), is useful to exclude character, but does not capture the rhythmicity and responsiveness to physiological stimuli (e.g., hot/cold, wet/dry, light/dark) that is prominent in classical concepts of temperament (Supplementary Table 1), the prominence of social attachments (sociable/aloof) (Tables 2-4), or in the molecular processes for regulation of diurnal and seasonal rhythms that we identified as fundamental features of the molecular pathways underlying temperament (Tables 2 and 6). We propose that only the form of learning (i.e., associative conditioning) and its evolutionary conservation are necessary and sufficient criteria for temperament because of the non-specificity of other criteria.

Several traditions that have approached temperament in different ways ${ }^{17}$ can now be recognized as converging and providing complementary information about how temperament and other aspects of personality develop across the life span. Defining temperament in terms of a specific and heritable form of learning makes it clear that distinctions between nature and nurture, biology and learning, genes and environment are inadequate. Temperament is the manifestation of a specific form of learning and memory, which is a non-linear dynamical process associated with complex patterns of inheritance and development. Individual differences in these adaptive processes are being investigated in terms of specific human brain functions using brain-imaging techniques ${ }^{96,97,126,183}$.

The temperament and character domains of personality do not function independently, so it is not surprising that investigators interested in temperament or personality often address similar questions. At times the overlap and interaction of temperament and character has led to confusion about what belongs to which domain because people function as whole organisms embedded in the world. We have identified the networks that integrate these domains and described their architecture, but there remains a need for further research to understand the integrative processes that bring the emotional reactivity of temperament together in balanced way with emotional regulation of character.

Personality research has closely aligned itself with temperament research by its emphasis on stability and use of similar methods based on assumptions of linear structure. However, it is crucial to recognize that personality has a complex biopsychosocial structure that is a product of interactions among multiple systems of learning memory that are dissociable functionally and developmentally.

Our findings about the complex genetics of temperament and character can best be understood from an evolutionary-developmental perspective. The evolutionary-developmental perspective helps to understand the adaptive functions of the molecular processes that distinguish temperament from other aspects of personality. The functions of the Ras-MEK-ERK and PI3KAKT-mTOR pathways serve to maintain cellular homeostasis, healthy functioning, and repair of injury and degeneration despite diurnal, seasonal, and climactic changes in a person's internal and external environment. Diverse stimuli can activate the molecular systems underlying temperament in coordinated ways that provide opportunities for effective interventions. However, there is great need for clinical trials to clarify how to use these natural stimuli effectively. As we begin to recognize that the psychobiological and genetic networks that regulate health and well-being correspond to systems of learning and memory, we have the opportunity and responsibility to develop and advocate an evidence-based approach to psychiatry that integrates knowledge about molecular, neurobiological, and psychosocial processes. The molecular aspects of psychiatry are only one level of organization that helps to open our eyes to the full multi-level organization of human functioning.

We have found that combining genotypic and phenotypic information does provide more information about health than does phenotypic information alone $e^{25,26}$. Consequently, genotypic panels for assessing the health propensities of people based on their personality are likely to be developed and offered commercially, as is being done for complex medical disorders. However, what has not been acknowledged by such commercial ventures is that the development of common disorders is highly complex and depends on the interaction of many sets of genotypic and environmental variables. Polygenic risk scores are not adequate for precise assessment of temperament because they rely on the average effects of genes acting independently, which can provide only weak and inconsistent information about personal health or risks of complex phenotypes in a specific individual (Supplementary Table 6) ${ }^{107}$. Even when complex phenomena (i.e., pleiotropy, epistasis, and gene-environment interaction) are taken into account, it turns out that the same genotypic profiles can be expressed in ways that are either healthy or unhealthy because of differences in the coherence of processes that regulate expression of genes and co-expression of sets of genes, often involving long non-coding RNA genes or a few "switch genes" that distinguish healthy and unhealthy character profiles ${ }^{25,27}$. For example, every possible TCI temperament profile can be either healthy or unhealthy, depending on a person's 
character profile; there are average differences in risk between profiles, but nothing can be said about how healthy a particular individual is from their temperament alone $^{14}$. Until we learn more about the processes that regulate the expression of protein-coding genes ${ }^{27}$, the additional costs and worries introduced by genetic testing of personality and/or common diseases may be unjustified when most information of practical value for personalized treatment planning is provided by improved phenotypic assessment at a lower cost. In addition, there are serious ethical issues concerning germline editing of the human genome to modify heritable human traits ${ }^{184}$. Our current reservations about the merits and dangers of introducing genotypic panels for enhanced personality assessment will need to be revisited once we gain more knowledge about the regulation of co-expression of sets of genes that lead to well-being and ill-being.

Psychopharmacology has already made substantial advances in developing treatments designed to target specific receptors, which can be an effective strategy when a small number of receptors cause a disorder consistently. However, when heterogeneous disorders depend on complex interactions among many genes and environmental variables, it is difficult or impossible to design interventions that are broadly effective and well tolerated.

Fortunately, we already know that the molecular mechanisms underlying temperaments evolved to help organisms adapt to naturally occurring physiological, psychosocial, and energetic stimuli, as was observed in antiquity. What is most important now is to consider how our molecular and clinical observations can be translated into useful interventions for disease reduction and health promotion. Use of cold (e.g., cryotherapy) ${ }^{185,186}$, heat (e.g., infrared light therapy ${ }^{187}$, light exposure (e.g., bright light therapy) ${ }^{188,189}$, patterned EMF (e.g., transcranial magnetic stimulation $)^{167}$, and lifestyle adjustments to optimize hydration, nutrition, exercise, and sleep ${ }^{190,191}$ have been widely advocated, but often produce weak and inconsistent results, particularly when there is inadequate motivation for change ${ }^{192}$ or limited understanding of the underlying mechanisms and the parameters critical for efficacy $^{193,194}$.

Furthermore, there is extensive evidence that treatments of temperament are most effective when treatment addresses all three systems of learning and memory in a coordinated manner: behavioral conditioning, intentional self-control, and self-aware evaluation need to be integrated in order to be strongly and consistently effective in promoting health and well-being ${ }^{27,190,195-198}$. Put another way, relating a person's current well-being to both their temperament and character provides powerful motivation for a person to change ${ }^{199}$. Fortunately, such thorough phenotypic assessments can also be expected to improve clinical trials by increasing study power in moderate-sized samples with stronger and more consistent results than have been obtained in poorly characterized and heterogeneous groups of subjects ${ }^{107}$.

\section{Acknowledgements}

This review was supported by the Anthropedia Foundation (C.R.C., K.M.C.), by grants from the NIH (5 R01 MH104414-02, 1 R41 HD097833-01) and the Spanish Ministerio de Ciencia y Tecnologia, para Proyectos de Investigacion Cientifica y Desarrollo Tecnologico (DPI2015-69585-R) (I.Z.), and the Young Finns Study (L.K.J.). The Young Finns Study has been financially supported by the Academy of Finland: grants 286284, 322098, 134309 (Eye), 126925, 121584 124282, 129378 (Salve), 117787 (Gendi), 41071 (Skidi), and 308676; the Social Insurance Institution of Finland; Competitive State Research Financing of the Expert Responsibility area of Kuopio, Tampere and Turku University Hospitals (grant X51001); Juho Vainio Foundation; Paavo Nurmi Foundation; Finnish Foundation for Cardiovascular Research; Finnish Cultural Foundation; Tampere Tuberculosis Foundation; Emil Aaltonen Foundation; Yrjö Jahnsson

Foundation; Signe and Ane Gyllenberg Foundation; Diabetes Research Foundation of Finnish Diabetes Association and EU Horizon 2020 (grant 755320 for TAXINOMISIS); Tampere University Hospital Supporting Foundation.

\section{Author details}

${ }^{1}$ Department of Psychiatry, Washington University School of Medicine, St. Louis, MO, USA. ${ }^{2}$ School of Arts and Sciences, Department of Psychological and Brain Sciences, and School of Medicine, Department of Genetics, Washington University, St. Louis, MO, USA. ${ }^{3}$ Anthropedia Foundation, St. Louis, MO, USA. ${ }^{4}$ Department of Computer Science, University of Granada, Granada, Spain. ${ }^{5}$ Department of Psychology and Logopedics, University of Helsinki, Helsinki, Finland

\section{Conflict of interest}

The authors declare that they have no conflict of interest.

\section{Publisher's note}

Springer Nature remains neutral with regard to jurisdictional claims in published maps and institutional affiliations.

Supplementary Information accompanies this paper at (https://doi.org/ 10.1038/s41398-019-0621-4).

Received: 27 June 2019 Revised: 25 September 2019 Accepted: 18 October 2019

Published online: 11 November 2019

\section{References}

1. Kagan, J. Galen's Prophecy: Temperament in Human Nature. (Basic Books, 1998).

2. Avicenna. The Canon of Medicine. 1-710 (KAZI Publications, 1999).

3. Kant, I. Anthropology from a Pragmatic Point of View. 1978 edn (Southern Illinois University Press, 1797).

4. Strelau, J. The regulative theory of temperament: current status. Personal. Individ. Differences 20, 131-142 (1996).

5. Thomas, A. \& Chess, S. Temperament and Development. (Brunner/Mazel, 1977).

6. Cloninger, C. R., Svrakic, D. M. \& Przybeck, T. R. A psychobiological model of temperament and character. Arch. Gen. Psychiatry 50, 975-990 (1993).

7. Goldsmith, H. H. et al. Roundtable: what is temperament? Four approaches. Child Dev. 58, 505-529 (1987).

8. Josefsson, $\mathrm{K}$. et al. Maturity and change in personality: developmental trends of temperament and character in adulthood. Dev. Psychopathol. 25, 713-727 (2013).

9. Cicchetti, D. \& Rogosch, F. A. Equifinality and multifinality in developmental psychopatology. Dev. Psychopathol. 8, 597-600 (1996).

10. Moffitt, T. E., Caspi, A., Harrington, H. \& Milne, B. J. Males on the life-coursepersistent and adolescence-limited antisocial pathways: follow-up at age 26 years. Dev. Psychopathol. 14, 179-207 (2002). 
11. Rettew, D. C., Althoff, R. R., Dumenci, L., Ayer, L. \& Hudziak, J. J. Latent profiles of temperament and their relations to psychopathology and wellness. J. Am. Acad. Child Adolesc. Psychiatry 47, 273-281 (2008)

12. Rettew, D. C. \& McKee, L. Temperament and its role in developmental psychopathology. Harv. Rev. Psychiatry 13, 14-27 (2005).

13. Cloninger, C. R. Feeling Good: The Science of Well-being. (Oxford University Press, 2004).

14. Cloninger, C. R., Svrakic, N. M. \& Svrakic, D. M. Role of personality selforganization in development of mental order and disorder. Dev. Psychopathol. 9, 881-906 (1997)

15. Vaillant, G. E. \& Vaillant, C. O. Natural history of male psychological health, XII: a 45-year study of predictors of successful aging at age 65. Am. J. Psychiatry 147, 31-37 (1990)

16. Dyson, M. W. et al. The structural and rank-order stability of temperament in young children based on a laboratory-observational measure. Psychol. Assess. 27, 1388-1401 (2015).

17. Shiner, R. L. et al. What is Temperament Now? Assessing progress in temperament research on the twenty-fifth anniversary of Goldsmith et al. (1987). Child Dev. Perspect. 6, 436-444 (2012).

18. Buss, A. H. in Explorations in Temperament: International Perspectives on Theory and Assessment (eds Strelau, J. \& Angleitner, A.) Ch. 3, 43-60 (Plenum Press, 1991).

19. Rothbart, M. K. Temperament, development and personality. Curr. Directions Psychological Sci. 16, 207-212 (2007).

20. Trofimova, I. \& Robbins, T. W. Temperament and arousal systems: a new synthesis of differential psychology and functional neurochemistry. Neurosci. Biobehav Rev. 64, 382-402 (2016).

21. Trofimova, I. An investigation into differences between the structure of temperament and the structure of personality. Am. J. Psychol. 123, 467-480 (2010).

22. Trofimova, I., Robbins, T. W., Sulis, W. H. \& Uher, J. Diverse perspectives on diversity: multi-disciplinary approaches to taxonomies of individual differences. Philos. Trans. R Soc. Lond. B Biol. Sci. 373, https://doi.org/10.1098/ rstb.2017.0163 (2018).

23. McCrae, R. R. et al. Nature over nurture: temperament, personality, and life span development. J. Pers. Soc. Psychol. 78, 173-186 (2000).

24. Kohnstamm, G. A., Halverson, C. F. J., Mervielde, I. \& Havill, V. L. in Personality and Clinical Psychology Series (ed. Weiner, I. B.) 222 (Lawrence Erlbaum Associates, Mahwah, NJ, 1998).

25. Zwir, I. et al. Uncovering the complex genetics of human character. Mol. Psychiatry, https://doi.org/10.1038/s41380-018-0263-6 (2018).

26. Zwir, l. et al. Uncovering the complex genetics of human temperament. Mol. Psychiatry, https://doi.org/10.1038/s41380-018-0264-5 (2018).

27. Zwir, I. et al. Three genetic-environmental networks for human personality. Mol. Psychiatry, https://doi.org/10.1038/s41380-019-0579-x (2019).

28. Caspi, A. et al. Children's behavioral styles at age 3 are linked to their adult personality traits at age 26. J. Pers. 71, 495-513 (2003).

29. Pesonen, A. K., Raikkonen, K., Keskivaara, P. \& Keltikangas-Jarvinen, L. Difficult temperament in childhood and adulthood: continuity from maternal perceptions to self-ratings over 17 years. Personal. Individ. Differences 34, 19-31 (2003).

30. Goldsmith, H. H. \& Campos, J. J. in The Development of Attachment and Affiliative Systems (eds Emde, R. N. \& Harmon, R. J.) 161-193 (Plenum, 1982).

31. Ekman, P. Are there basic emotions? Psychol. Rev. 99, 550-553 (1992).

32. Sauter, D. A., Eisner, F., Ekman, P. \& Scott, S. K. Cross-cultural recognition of basic emotions through nonverbal emotional vocalizations. Proc. Natl Acad. Sci. USA 107, 2408-2412 (2010).

33. Plutchik, R. The nature of emotions. Ameican Scientist 89, 344-350 (2001).

34. Izard, C. E. Basic emotions, natural kinds, emotion schemas, and a new paradigm. Perspect. Psychol. Sci. 2, 260-280 (2007).

35. Loehlin, J. C. Genes and Environment in Personality Development. (Sage Publications, 1992).

36. Bouchard, T. J. Jr. \& Loehlin, J. C. Genes, evolution, and personality. Behav. Genet 31, 243-273 (2001)

37. Loehlin, J. C. \& Gough, H. G. Genetic and environmental variation on the California Psychological Inventory vector scales. J. Pers. Assess. 54, 463-468 (1990)

38. Darwin, C. The Expression of The Emotions in Man and Animals; with an introduction, afterword and commentaries by Paul Ekman; Essay on the history of the illustrations by Phillip Prodger. Ekman's edition edn (HarperCollins Publishers, 1998).
39. Cloninger, C. R. The genetic structure of personality and learning: a phylogenetic model. Clin. Genet 46, 124-137 (1994).

40. MacLean, P. D. Brain evolution relating to family, play, and the separation call. Arch. Gen. Psychiatry 42, 405-417 (1985).

41. Gillespie, N. A., Cloninger, C. R., Heath, A. C. \& Martin, N. G. The genetic and environmental relationship between Cloninger's dimensions of temperament and character. Personal. Individ. Differences 35, 1931-1946 (2003).

42. Cloninger, C. R. The evolution of human brain functions: the functional structure of human consciousness. Aust. N.Z. J. Psychiatry 43, 994-1006 (2009).

43. Allman, J. M. et al. The von Economo neurons in the frontoinsular and anterior cingulate cortex. Ann. N. Y Acad. Sci. 1225, 59-71 (2011).

44. Tulving, E. Episodic memory: from mind to brain. Annu Rev. Psychol. 53, 1-25 (2002).

45. Tulving, E. Multiple memory systems and consciousness. Hum. Neurobiol. 6 , 67-80 (1987).

46. Levine, B. Autobiographical memory and the self in time: brain lesion effects, functional neuroanatomy, and lifespan development. Brain Cognition 55, 54-68 (2004).

47. Josefsson, K. et al. Parental care-giving and home environment predicting offspring temperament and character traits after 18 years. Psychiatry Res. 209 643-651 (2013).

48. Constantino, J. N., Cloninger, C. R., Clarke, A. R., Hashemi, B. \& Przybeck, T. Application of the seven-factor model of personality to early childhood. Psychiatry Res. 109, 229-243 (2002).

49. Zohar, A. H., Zwir, I., Wang, J., Cloninger, C. R. \& Anokhin, A. P. The development of temperament and character during adolescence: the processes and phases of change. Dev. Psychopathol. 31, 601-617 (2019).

50. Fang, Y. \& Fullwood, M. J. Roles, functions, and mechanisms of long noncoding RNAs in cancer. Genomics Proteom. Bioinforma. 14, 42-54, https://doi. org/10.1016/j.gpb.2015.09.006 (2016).

51. Quinn, J. J. \& Chang, H. Y. Unique features of long non-coding RNA biogenesis and function. Nat. Rev. Genet 17, 47-62 (2016).

52. Barbash, S. et al. Neuronal-expressed microRNA-targeted pseudogenes compete with coding genes in the human brain. Transl. Psychiatry 7, e1199 (2017).

53. Faraone, S. V. The omnigenic model: implications for psychiatric genetics. J. Psychiatry Brain Sci. 2(S1), 1-2 (2017)

54. Hess, J. L., Akutagava-Martins, G. C., Patak, J. D., Glatt, S. J. \& Faraone, S. V. Why is there selective subcortical vulnerability in ADHD? Clues from postmortem brain gene expression data. Mol. Psychiatry 23, 1787-1793 (2018).

55. Cloninger, C. R. \& Svrakic, D. M. in Kaplan and Sadock's Comprehensive Textbook of Psychiatry Vol. 1 (eds Sadock, B. J., Sadock, V. A. \& Ruiz, P.) Ch. 26, 2126-2176 (Lippincott Williams \& Wilkins, 2017).

56. Cloninger, C. R. Temperament and personality. Curr. Opin. Neurobiol. 4, 266-273 (1994).

57. Corr, P. J., Kumari, V., Wilson, G. D., Checkley, S. \& Gray, J. A. Harm Avoidance and affective modulation of the startle reflex: a replication. Personal. Individ. Differences 22, 591-593 (1997).

58. Corr, P. J., Pickering, A. D. \& Gray, J. A. Personality and reinforcement in associative and instrumental learning. Personal. Individ. Differences 19, 47-71 (1995).

59. Pezawas, L. et al. 5-HTTLPR polymorphism impacts human cingulateamygdala interactions: a genetic susceptibility mechanism for depression Nat. Neurosci. 8, 828-834 (2005).

60. Houillon, A. et al. The effect of novelty on reinforcement learning. Prog. Brain Res. 202, 415-439 (2013).

61. Krebs, R. M., Schott, B. H. \& Duzel, E. Personality traits are differentially associated with patterns of reward and novelty processing in the human substantia nigra/ventral tegmental area. Biol. Psychiatry 65, 103-110 (2009).

62. Gusnard, D. A. et al. Persistence and brain circuitry. Proc. Natl Acad. Sci. USA 100, 3479-3484 (2003)

63. Cloninger, C. R., Zohar, A. H., Hirschmann, S. \& Dahan, D. The psychological costs and benefits of being highly persistent: personality profiles distinguish mood disorders from anxiety disorders. J. Affect. Disord. 136, 758-766 (2012).

64. Yang, T. T. et al. Adolescent subgenual anterior cingulate activity is related to harm avoidance. Neuroreport 20, 19-23 (2009).

65. Paulus, M. P., Rogalsky, C., Simmons, A., Feinstein, J. S. \& Stein, M. B. Increased activation in the right insula during risk-taking decision making is related to harm avoidance and neuroticism. Neuroimage 19, 1439-1448 (2003). 
66. Naghavi, H. R., Lind, J., Nilsson, L. G., Adolfsson, R. \& Nyberg, L. Personality traits predict response to novel and familiar stimuli in the hippocampal region. Psychiatry Res. 173, 94-99 (2009).

67. Lei, X. et al. Fiber connectivity between the striatum and cortical and subcortical regions is associated with temperaments in Chinese males. Neuroimage 89, 226-234 (2014).

68. Tost, $\mathrm{H}$. et al. A common allele in the oxytocin receptor gene (OXTR) impacts prosocial temperament and human hypothalamic-limbic structure and function. Proc. Natl Acad. Sci. USA 107, 13936-13941 (2010).

69. Hornowska, E. Cloninger's psychobiological model of personality and Strelau's regulative theory of temperament-analysis of their associations in a Polish sample. Pol. Psychological Bull. 42, 71080 (2011).

70. Windle, M. Temperament and social support in adolescence: Interrelations with depressive symptoms and delinquent behaviors. J. Youth Adolesc. 21 1-21, https://doi.org/10.1007/BF01536980 (1992).

71. Puttonen, S. Common Elements of Five Temperament Models. MA thesis, University of Helsinki (2005).

72. Rowe, D. C. \& Plomin, R. Temperament in early childhood. J. Pers. Assess. 41, 150-156 (1977).

73. Kitamura, T. et al. Emotionality Activity Sociability and Impulsivity (EASI) Survey: psychometric properties and assessment of the Japanese version. Psychol. Behav. Sci. 3, 113-120 (2014).

74. Buss, A. H. \& Plomin, R. Temperament: Early Developing Personality Traits. (Lawrence Erlbaum, 1984).

75. Thomas, A., Chess, S. \& Birch, H. G. The origin of personality. Sci. Am. 223, 102-109 (1970).

76. Thomas, A., Chess, S. \& Birch, H. G. Temperament and Behavior Disorders in Children. (New York University Press, 1968).

77. Carey, W. B. \& McDevitt, S. C. Stability and change in individual temperament diagnoses from infancy to early childhood. J. Am. Acad. Child Psychiatry 17, 331-337 (1978).

78. Prior, M. Childhood temperament. J. Child Psychol. Psychiatry 33, 249-279 (1992).

79. Mathiesen, K. S. \& Tambs, K. The EAS temperament questionnaire-factor structure, age trends, reliability, and stability in a Norwegian sample. J. Child Psychol. Psychiatry 40, 431-439 (1999).

80. Rende, R. D. Longitudinal relations between temperament traits and behavioral syndromes in middle childhood. J. Am. Acad. Child Adolesc. Psychiatry 32, 287-290 (1993)

81. Westen, D. \& Shedler, J. A prototype matching approach to diagnosing personality disorders: toward DSM-V. J. Pers. Disord. 14, 109-126 (2000).

82. Evans, D. E. \& Rothbart, M. K. Developing a model for adult temperament. J. Res. Personal. 41, 868-888 (2007).

83. Zuckerman, M. \& Cloninger, C. R. Relationship between Cloninger's, Zuckerman's, and Eysenck's dimensions of personality. Personal. Individ. Differences 21, 283-285 (1996).

84. Cloninger, C. R. Personality and temperament: New and alternative perspectives. Focus (Am. Psychiatr. Publ.) 8, 161-163 (2010).

85. Hopwood, C. J. \& Donnellan, M. B. How should the internal structure of personality inventories be evaluated? Pers. Soc. Psychol. Rev. 14, 332-346 (2010).

86. Ropovik, I. A cautionary note on testing latent variable models. Front Psychol. 6, 1715 (2015).

87. Hayes, A. M., Laurenceau, J. P., Feldman, G., Strauss, J. L. \& Cardaciotto, L. Change is not always linear: the study of nonlinear and discontinuous patterns of change in psychotherapy. Clin. Psychol. Rev. 27, 715-723 (2007).

88. Lemery-Chalfant, K., Doelger, L. \& Goldsmith, H. H. Genetic relations between effortful and attentional control and symptoms of psychopathology in middle childhood. Infant Child Dev. 17, 365-385 (2008).

89. Tulving, E. Episodic memory and common sense: how far apart? Philos. Trans. R. Soc. Lond., B Biol. Sci. 356, 1505-1515 (2001).

90. Cloninger, C. R. \& Zwir, I. What is the natural measurement unit of temperament: single traits or profiles? Philos. Trans. R Soc. Lond. B Biol. Sci. $\mathbf{3 7 3}$ https://doi.org/10.1098/rstb.2017.0163 (2018).

91. Cloninger, C. R. A unified biosocial theory of personality and its role in the development of anxiety states. Psychiatr. Dev. 4, 167-226 (1986).

92. Cloninger, C. R. A systematic method for clinical description and classification of personality variants. A proposal. Arch. Gen. Psychiatry 44, 573-588 (1987).

93. Hansenne, M. \& Ansseau, M. Catecholaminergic function and temperament in major depressive disorder: a negative report. Psychoneuroendocrinology $\mathbf{2 3}$ 477-483 (1998).
94. Cloninger, C. R. \& Gilligan, S. B. Neurogenetic mechanisms of learning: a phylogenetic perspective. J. Psychiatr. Res. 21, 457-472 (1987).

95. Cloninger, C. R. \& Kedia, S. in The Origins of Cooperation and Altruism Developments in Primatology: Progress and Prospects (eds Sussman, R. W. \& Cloninger, C. R.) 63-110 (Springer, 2011).

96. Van Schuerbeek, P., Baeken, C., De Raedt, R., De Mey, J. \& Luypaert, R. Individual differences in local gray and white matter volumes reflect differences in temperament and character: a voxel-based morphometry study in healthy young females. Brain Res. 1371, 32-42 (2011).

97. Gardini, S., Cloninger, C. R. \& Venneri, A. Individual differences in personality traits reflect structural variance in specific brain regions. Brain Res. Bull. 79 265-270 (2009).

98. Povinelli, D. J. Folk Physics for Apes: the Chimpanzee's Theory of How the World Works. (Oxford University Press, 2000).

99. Ullman, M. T. A neurocognitive perspective on language: the declarative/ procedural model. Nat. Rev. Neurosci. 2, 717-726 (2001).

100. Lee, A. C., Robbins, T. W., Graham, K. S. \& Owen, A. M. "Pray or Prey?" dissociation of semantic memory retrieval from episodic memory processes using positron emission tomography and a novel homophone task. Neuroimage 16, 724-735 (2002)

101. Levine, B. et al. The functional neuroanatomy of episodic and semantic autobiographical remembering: a prospective functional MRI study. J. Cogn. Neurosci. 16, 1633-1646 (2004).

102. Finn, A. S. et al. Developmental dissociation between the maturation of procedural memory and declarative memory. J. Exp. Child Psychol. 142, 212-220 (2016).

103. Nissen, M. J., Knopman, D. S. \& Schacter, D. L. Neurochemical dissociation of memory systems. Neurology 37, 789-794 (1987).

104. Graham, K. S., Simons, J. S., Pratt, K. H., Patterson, K. \& Hodges, J. R. Insights from semantic dementia on the relationship between episodic and semantic memory. Neuropsychologia 38, 313-324 (2000).

105. Svoboda, E., McKinnon, M. C. \& Levine, B. The functional neuroanatomy of autobiographical memory: a meta-analysis. Neuropsychologia 44, 2189-2208 (2006).

106. Fink, A. et al. Modulation of resting-state network connectivity by verbal divergent thinking training. Brain Cogn. 128, 1-6 (2018).

107. Zwir, l. et al. Uncovering the complex genetics of human personality: response from authors on the PGMRA Model. Mol. Psychiatry, https://doi.org/ 10.1038/s4138-019-0399-z (2019).

108. Keller, M. C., Coventry, W. L., Heath, A. C. \& Martin, N. G. Widespread evidence for non-additive genetic variation in Cloninger's and Eysenck's Personality Dimensions using a Twin Plus Sibling Design. Behav. Genet. 35, 707-721 (2005)

109. Eaves, L. J., Heath, A. C., Neale, M. C., Hewitt, J. K. \& Martin, N. G. Sex differences and non-additivity in the effects of genes on personality. Twin Res. 1, 131-137 (1998).

110. Eaves, L. J. et al. Comparing the biological and cultural inheritance of personality and social attitudes in the Virginia 30,000 study of twins and their relatives. Twin Res. 2, 62-80 (1999).

111. Lake, R. I., Eaves, L. J., Maes, H. H., Heath, A. C. \& Martin, N. G. Further evidence against the environmental transmission of individual differences in neuroticism from a collaborative study of 45,850 twins and relatives on two continents. Behav. Genet 30, 223-233 (2000).

112. Finkel, D. \& McGue, M. Sex differences and nonadditivity in heritability of the Multidimensional Personality Questionnaire Scales. J. Pers. Soc. Psychol. 72, 929-938 (1997).

113. Verweij, K. J. et al. Maintenance of genetic variation in human personality: testing evolutionary models by estimating heritability due to common causal variants and investigating the effect of distant inbreeding. Evolution 66, 3238-3251 (2012).

114. Vinkhuyzen, A. A. et al. Common SNPs explain some of the variation in the personality dimensions of neuroticism and extraversion. Transl. Psychiatry $\mathbf{2}$ e102 (2012).

115. Power, R. A. \& Pluess, M. Heritability estimates of the Big Five personality traits based on common genetic variants. Transl. Psychiatry $\mathbf{5}$ e604 (2015).

116. Genetics of Personality, C. et al. Meta-analysis of genome-wide association studies for neuroticism, and the polygenic association with major depressive disorder. JAMA Psychiatry 72, 642-650 (2015).

117. Smith, D. J. et al. Genome-wide analysis of over 106000 individuals identifies 9 neuroticism-associated loci. Mol. Psychiatry 21, 1644 (2016). 
118. Docherty, A. R. et al. SNP-based heritability estimates of the personality dimensions and polygenic prediction of both neuroticism and major depression: findings from CONVERGE. Transl. Psychiatry 6, e926 (2016).

119. Lo, M. T. et al. Genome-wide analyses for personality traits identify six genomic loci and show correlations with psychiatric disorders. Nat. Genet 49, 152-156 (2017).

120. Okbay, A. et al. Genetic variants associated with subjective well-being depressive symptoms, and neuroticism identified through genome-wide analyses. Nat. Genet 48, 624-633 (2016).

121. Luciano, M. et al. Association analysis in over 329,000 individuals identifies 116 independent variants influencing neuroticism. Nat. Genet 50, 6-11 (2018)

122. Nagel, M. et al. Meta-analysis of genome-wide association studies for neuroticism in 449,484 individuals identifies novel genetic loci and pathways. Nat. Genet 50, 920-927 (2018)

123. van den Berg, S. M. et al. Meta-analysis of genome-wide association studies for extraversion: findings from the genetics of personality consortium. Behav. Genet. 46, 170-182 (2016)

124. Zwir, I. et al. Dissecting the PhoP regulatory network of Escherichia coli and Salmonella enterica. Proc. Natl Acad. Sci. USA 102, 2862-2867 (2005).

125. Zwir, l., Huang, H. \& Groisman, E. A. Analysis of differentially-regulated genes within a regulatory network by GPS genome navigation. Bioinformatics $\mathbf{2 1}$ 4073-4083 (2005).

126. Arnedo, J. et al. Decomposition of brain diffusion imaging data uncovers latent schizophrenias with distinct patterns of white matter anisotropy. Neuroimage 120, 43-54 (2015).

127. Arnedo, J. et al. Uncovering the hidden risk architecture of the schizophrenias: confirmation in three independent genome-wide association studies. Am. J. Psychiatry 172, 139-153 (2015).

128. Arnedo, J. et al. PGMRA: a web server for (phenotype $x$ genotype) many-tomany relation analysis in GWAS. Nucleic Acids Res. 41, W142-149 (2013).

129. Raitakari, O. T. et al. Cohort profile: the cardiovascular risk in Young Finns Study. Int J. Epidemiol. 37, 1220-1226 (2008).

130. Cook, T. B. et al. Latent infection with Toxoplasma gondii: association with trait aggression and impulsivity in healthy adults. J. Psychiatr. Res. 60, 87-94 (2015)

131. Gombojav, B. et al. The Healthy Twin Study, Korea updates: resources for omics and genome epidemiology studies. Twin Res. Hum. Genet. 16, 241-245 (2013)

132. Sung, J. et al. Healthy Twin: a twin-family study of Korea-protocols and current status. Twin Res. Hum. Genet 9, 844-848 (2006).

133. Deb, K. Multi-objective Optimization Using Evolutionary Algorithms. 1st edn, 497 (John Wiley \& Sons, 2001).

134. Luscher, C. \& Malenka, R. C. NMDA receptor-dependent long-term potentiation and long-term depression (LTP/LTD). Cold Spring Harb. Perspect. Biol. 4 1-16 (2012).

135. Peng, S., Zhang, Y., Zhang, J., Wang, H. \& Ren, B. ERK in learning and memory: a review of recent research. Int J. Mol. Sci. 11, 222-232 (2010).

136. Tronson, N. C., Corcoran, K. A., Jovasevic, V. \& Radulovic, J. Fear conditioning and extinction: emotional states encoded by distinct signaling pathways. Trends Neurosci. 35, 145-155 (2012).

137. Brems, B. Spontaneous decisions and operant conditioning in fruit flies. Behav. Process. 87, 157-164 (2011).

138. Rapanelli, M., Frick, L. R. \& Zanutto, B. S. Differential gene expression in the rat hippocampus during learning of an operant conditioning task. Neuroscience 163, 1031-1038 (2009)

139. Atkins, C. M., Selcher, J. C., Petraitis, J. J., Trzaskos, J. M. \& Sweatt, J. D. The MAPK cascade is required for mammalian associative learning. Nat. Neurosci. 1, 602-609 (1998).

140. Sakai, N., Ohno, H., Tomioka, M. \& lino, Y. The intestinal TORC2 signaling pathway contributes to associative learning in Caenorhabditis elegans. PLoS ONE 12, e0177900 (2017)

141. Diamond, D. M., Park, C. R., Campbell, A. M. \& Woodson, J. C. Competitive interactions between endogenous LTD and LTP in the hippocampus underlie the storage of emotional memories and stress-induced amnesia. Hippocampus 15, 1006-1025 (2005).

142. Rapanelli, M., Frick, L. R. \& Zanutto, B. S. Learning an operant conditioning task differentially induces gliogenesis in the medial prefrontal cortex and neurogenesis in the hippocampus. PLOS ONE 6, e14713 (2011).

143. Rapanelli, M., Frick, L. R., Bernardez-Vidal, M. \& Zanutto, B. S. Different MK-801 administration schedules induce mild to severe learning impairments in an operant conditioning task: role of buspirone and risperidone in ameliorating these cognitive deficits. Behav. Brain Res. 257, 156-165 (2013).

144. Swanson, J. M. et al. Etiologic subtypes of attention-deficit/hyperactivity disorder: brain imaging, molecular genetic and environmental factors and the dopamine hypothesis. Neuropsychol. Rev. 17, 39-59 (2007).

145. Ramanathan, $\mathrm{C}$. et al. mTOR signaling regulates central and peripheral circadian clock function. PLoS Genet 14, e1007369 (2018).

146. Mendoza, M. C., Er, E. E. \& Blenis, J. The Ras-ERK and PI3K-mTOR pathways: cross-talk and compensation. Trends Biochem Sci. 36, 320-328 (2011).

147. Fruman, D. A. et al. The PI3K pathway in human disease. Cell 170, 605-635 (2017).

148. Steelman, L. S. et al. Roles of the Raf/MEK/ERK and PI3K/PTEN/Akt/mTOR pathways in controlling growth and sensitivity to therapy-implications for cancer and aging. Aging (Albany NY) 3, 192-222 (2011).

149. Lee, M., Sorn, S. R., Lee, Y. \& Kang, I. Salt induces adipogenesis/lipogenesis and inflammatory adipocytokines secretion in adipocytes. Int. J. Mol. Sci. 20, https://doi.org/10.3390/ijms20010160 (2019).

150. Liong, S., Barker, G. \& Lappas, M. Placental ras regulates inflammation associated with maternal obesity. Mediators Inflamm. 2018, 3645386 (2018).

151. Hintsanen, M. et al. Negative emotionality, activity, and sociability temperaments predicting long-term job strain and effort-reward imbalance: a 15-year prospective follow-up study. J. Psychosom. Res. 71, 90-96 (2011).

152. Wessman, J. et al. Temperament clusters in a normal population: implications for health and disease. PLoS One 7, e33088 (2012).

153. Hintsanen, M. et al. Cloninger's temperament traits and preclinical atherosclerosis: the Cardiovascular Risk in Young Finns Study. J. Psychosom. Res. 67, 77-84 (2009).

154. Chan, E. Y., Stang, S. L., Bottorff, D. A. \& Stone, J. C. Hypothermic stress leads to activation of Ras-Erk signaling. J. Clin. Invest 103, 1337-1344 (1999).

155. Molina, J. R. \& Adjei, A. A. The Ras/Raf/MAPK pathway. J. Thorac. Oncol. 1, 7-9 (2006).

156. Yoshihara, T. et al. Heat stress activates the Akt/mTOR signalling pathway in rat skeletal muscle. Acta Physiol. (Oxf.) 207, 416-426 (2013).

157. Kakigi, R. et al. Heat stress enhances mTOR signaling after resistance exercise in human skeletal muscle. J. Physiol. Sci. 61, 131-140 (2011).

158. Gomes, A. P. \& Adjei, A. A. A nexus for cellular homeostasis: the interplay between metabolic and signal transduction pathways. Curr. Opin. Biotechnol. 34, 110-117 (2015)

159. Zhang, K. et al. Light-mediated kinetic control reveals the temporal effect of the Raf/MEK/ERK pathway in PC12 cell neurite outgrowth. PLOS ONE $\mathbf{9}$ e92917 (2014).

160. Krishnamurthy, V. V. et al. Light-mediated reversible modulation of the mitogen-activated protein kinase pathway during cell differentiation and xenopus embryonic development. J. Vis. Exp. https://doi.org/10.3791/55823 (2017).

161. Caraglia, M. et al. Electromagnetic fields at mobile phone frequency induce apoptosis and inactivation of the multi-chaperone complex in human epidermoid cancer cells. J. Cell Physiol. 204, 539-548 (2005).

162. Pall, M. L. Microwave frequency electromagnetic fields (EMFs) produce widespread neuropsychiatric effects including depression. J. Chem. Neuroanat. 75, 43-51 (2016)

163. Altun, G. et al. Protective effects of melatonin and omega-3 on the hippocampus and the cerebellum of adult Wistar albino rats exposed to electromagnetic fields. J. Microsc Ultrastruct. 5, 230-241 (2017).

164. Buckner, C. A., Buckner, A. L., Koren, S. A., Persinger, M. A. \& Lafrenie, R. M. Exposure to a specific time-varying electromagnetic field inhibits cell proliferation via CAMP and ERK signaling in cancer cells. Bioelectromagnetics 39 , 217-230 (2018).

165. Rouleau, N. \& Dotta, B. T. Electromagnetic fields as structure-function zeitgebers in biological systems: environmental orchestrations of morphogenesis and consciousness. Front Integr. Neurosci. 8, 84 (2014).

166. Singh, A. et al. Personalized repetitive transcranial magnetic stimulation temporarily alters default mode network in healthy subjects. Sci. Rep. 9, 5631 (2019).

167. Siddiqi, S. H., Chockalingam, R., Cloninger, C. R., Lenze, E. J. \& Cristancho, P. Use of the temperament and character inventory to predict response to repetitive transcranial magnetic stimulation for major depression. J. Psychiatr. Pr. 22, 193-202 (2016).

168. Wang, J. Q. \& Mao, L. The ERK pathway: molecular mechanisms and treatment of depression. Mol. Neurobiol. (2019). 
169. Schliess, F., Richter, L., vom Dahl, S. \& Haussinger, D. Cell hydration and mTOR-dependent signalling. Acta Physiol. 187, 223-229 (2006).

170. Vitalini, M. W. et al. Circadian rhythmicity mediated by temporal regulation of the activity of p38 MAPK. Proc. Natl Acad. Sci. USA 104, 18223-18228 (2007)

171. Dubbelhuis, P. F. \& Meijer, A. J. Hepatic amino acid-dependent signaling is under the control of AMP-dependent protein kinase. FEBS Lett. 521, 39-42 (2002).

172. Howell, J. J. et al. Metformin inhibits hepatic mTORC1 signaling via dosedependent mechanisms involving AMPK and the TSC complex. Cell Metab. 25, 463-471 (2017).

173. Wright, D. C. et al. Exercise-induced mitochondrial biogenesis begins before the increase in muscle PGC-1alpha expression. J. Biol. Chem. 282, 194-199 (2007).

174. Wright, D. C., Geiger, P. C., Han, D. H., Jones, T. E. \& Holloszy, J. O. Calcium induces increases in peroxisome proliferator-activated receptor gamma coactivator-1alpha and mitochondrial biogenesis by a pathway leading to p38 mitogen-activated protein kinase activation. J. Biol. Chem. 282, 18793-18799 (2007).

175. Perry, C. G. R. Mitochondrial adaptations to exercise in human skeletal muscle: a possible role for cristae density as a determinant of muscle fitness. J. Physiol. 595, 2773-2774 (2017).

176. Miao, S., Liu, Y., Zhang, L., Shan, M. \& Miao, Z. Effects of MAPK/ERK pathway on learning and memory in sleep deprivation rats. Int. J. Clin. Exp. Med. 11, 9160-9166 (2018).

177. Perogamvros, L. et al. Increased reward-related behaviors during sleep and wakefulness in sleepwalking and idiopathic nightmares. PLOS ONE 10 e0134504 (2015).

178. Mikhail, C., Vaucher, A., Jimenez, S. \& Tafti, M. ERK signaling pathway regulates sleep duration through activity-induced gene expression during wakefulness. Sci. Signal. 10, https://doi.org/10.1126/scisignal.aai9219 (2017).

179. Randler, C. \& Saliger, L. Relationship between morningness-eveningness and temperament and character dimensions in adolescents. Personal. Individ. Differences 50, 148-152 (2011).

180. Johansson, C. et al. Circadian clock-related polymorphisms in seasonal affective disorder and their relevance to diurnal preference. Neuropsychopharmacology 28, 734-739 (2003).

181. Chotai, J. Novelty seekers and summer-borns are likely to be low in morningness. Eur. Psychiatry 20, 307 (2005).

182. Chotai, J., Joukamaa, M., Taanila, A., Lichtermann, D. \& Miettunen, J. Novelty seeking among adult women is lower for the winter borns compared to the summer borns: replication in a large Finnish birth cohort. Compr. Psychiatry 50, 562-566 (2009)

183. Van Schuerbeek, P., Baeken, C., Luypaert, R., De Raedt, R. \& De Mey, J. Does the amygdala response correlate with the personality trait 'harm avoidance' while evaluating emotional stimuli explicitly? Behav. Brain Funct. 10, 18 (2014).
184. Lander, E. S. et al. Adopt a moratorium on heritable genome editing. Nature 567, 165-168 (2019).

185. Bleakley, C. M., Bieuzen, F., Davison, G. W. \& Costello, J. T. Whole-body cryotherapy: empirical evidence and theoretical perspectives. Open Access $J$. Sports Med. 5, 25-36 (2014).

186. Costello, J. T. et al. Whole-body cryotherapy (extreme cold air exposure) for preventing and treating muscle soreness after exercise in adults. Cochrane Database SystRev CD010789, https://doi.org/10.1002/14651858.CD010789. pub2 (2015)

187. Shui, S., Wang, X., Chiang, J. Y. \& Zheng, L. Far-infrared therapy for cardiovascular, autoimmune, and other chronic health problems: a systematic review. Exp. Biol. Med. (Maywood) 240, 1257-1265 (2015).

188. Oldham, M. A. \& Ciraulo, D. A. Bright light therapy for depression: a review of its effects on chronobiology and the autonomic nervous system. Chronobiol. Int 31, 305-319 (2014)

189. Reichborn-Kjennerud, T. \& Lingjaerde, O. Response to light therapy in seasonal affective disorder: personality disorders and temperament as predictors of outcome. J. Affect Disord. 41, 101-110 (1996).

190. Nigg, C. R. et al. Stages of change across ten health risk behaviors for older adults. Gerontologist 39, 473-482 (1999).

191. Prochaska, J. O. et al. Multiple risk expert systems interventions: impact of simultaneous stage-matched expert system interventions for smoking, highfat diet, and sun exposure in a population of parents. Health Psychol. 23, 503-516 (2004).

192. Kobau, R., Sniezek, J., Zack, M. M., Lucas, R. E. \& Adam, B. Well-being assessment: An evaluation of well-being scales for public health and population stimates of well-being among US adults. Appl. Psychol. 2, 272-297 (2010).

193. Krueger, M., Costello, J. T., Achtzehn, S., Dittmar, K. H. \& Mester, J. Whole-body cryotherapy (-110 degrees C) following high-intensity intermittent exercise does not alter hormonal, inflammatory or muscle damage biomarkers in trained males. Cytokine 113, 277-284 (2019).

194. Polidori, G. et al. Should whole body cryotherapy sessions be differentiated between women and men? A preliminary study on the role of the body thermal resistance. Med Hypotheses 120, 60-64 (2018).

195. Cloninger, C. R. \& Cloninger, K. M. People create health: Effective health promotion is a creative process. International. J. Pers.-centered Med. $\mathbf{3}, 114-122$ (2013).

196. Mirowsky, J. \& Ross, C. E. Education, personal control, lifestyle and health: a human capital hypothesis. Res. Aging 20, 415-449 (1998).

197. Hayes, S. A., Orsillo, S. M. \& Roemer, L. Changes in proposed mechanisms of action during an acceptance-based behavior therapy for generalized anxiety disorder. Behav. Res Ther. 48, 238-245 (2010).

198. Cloninger, C. R. Person-centered health promotion in chronic disease. Int. J. Pers.-centered Med. 3, 5-12 (2013).

199. Cloninger, C. R. \& Cloninger, K. M. Person-centered therapeutics. Int. J. Pers.centered Med. 1, 43-52 (2011). 